\title{
Hybrid Micro-machining Processes: A Review
}

\author{
Saeed Zare Chavoshi, Xichun Luo* \\ Centre for Precision Manufacturing, Department of Design, Manufacture and Engineering \\ Management, University of Strathclyde, Glasgow, G1 1XJ, UK \\ *xichun.luo@strath.ac.uk
}

\begin{abstract}
Micro-machining has attracted great attention as micro-components/products such as microdisplays, micro-sensors, micro-batteries, etc. are becoming established in all major areas of our daily life and can already been found across the broad spectrum of application areas especially in sectors such as automotive, aerospace, photonics, renewable energy and medical instruments. These micro-components/products are usually made of multi-materials (may include hard-to-machine materials) and possess complex shaped micro-structures but demand sub-micron machining accuracy. A number of micro-machining processes is therefore, needed to deliver such components/products. The paper reviews recent development of hybrid micro-machining processes which involve integration of various micro-machining processes with the purpose of improving machinability, geometrical accuracy, tool life, surface integrity, machining rate and reducing the process forces. Hybrid micro-machining processes are classified in two major categories namely, assisted and combined hybrid micromachining techniques. The machining capability, advantages and disadvantages of the stateof-the-art hybrid micro-machining processes are characterized and assessed. Some case studies on integration of hybrid micro-machining with other micro-machining and assisted
\end{abstract}


techniques are also introduced. Possible future efforts and developments in the field of hybrid micro-machining processes are also discussed.

Keywords: Micro-component; Hybrid micro-machining; Process integration

\section{Nomenclature}

BUE built-up edge

CCM conventional cutting method

CIRP college international pour la recherche en productique

CUSM chemical-assisted ultrasonic machining

DC direct current

ECAM electrochemical arc machining

ECDM electrochemical discharge machining

ECM electrochemical machining

ECSM electrochemical spark machining

EDM electrodischarge machining

EMM electrochemical micro-machining

ERP electrorheological fluid-assisted polishing

EVC elliptical vibration cutting 
EWR electrode wear rate

FEM finite element method

FTS fast tool servo

HAZ heat-affected zone

HF hydrofluoric

HFDG high frequency dither grinding

JECM jet electrochemical machining

LAJECM laser-assisted jet electrochemical machining

LAMM laser-assisted micro-milling

MRR material removal rate

PET polyethylene terephthalate

PMMA polymethyl methacrylate

$\mathrm{RC}$ resistor-capacitor

R-MEDM reverse micro-electrical discharge machining

ROC radial overcut

SACE spark-assisted chemical engraving

SEDCM simultaneous micro-EDM and micro-ECM

SEM scanning electron microscope

TBC thermal barrier coating 
USM ultrasonic machining

UV ultraviolet

WC tungsten carbide

WEDG wire electrodischarge grinding

WEDM wire electrodischarge machining

\section{Introduction}

In recent years, the demand for micro-components/products has increased at a rapid pace in various areas such as electronics, bio-medical, aviation, energy and optical industries [1]. The characteristics of these micro-components/products are: 1) size of functional features in micrometre level, from few micrometres up to 100 micrometres; 2) high precision tolerances, typically better than 1 micrometre; 3) good surface finish, in general surface roughness $\mathrm{Ra}$ smaller than half micrometre; 4) 3D or complicated structures; 5) use of a variety of materials such as ceramics, hard steels, titanium alloys, etc. [2]. Many surface or bulk micro-machining processes based on lithography, chemical or plasma etching, printing, moulding, transfer and assembly techniques have been proposed for micro/nano-device batch fabrication [3-4]. They can provide components with small feature sizes in inorganic and organic materials and even 3D shapes. Micro-machining techniques reviewed in this paper are fully complementary techniques able to provide complex geometries in a large range of materials with a high relative accuracy. They constitute a promising technology for bridging the gap between macro and micro/nano domains [5-7]. 
Although traditional stand-alone (single function) machine tools have been used as a major means to fabricate micro-components/products, it still remains a big issue in the predictability, producibility and productivity of fabrication of micro-components/products, especially for those with complex surface forms/shapes [8]. In recent years some multifunctional machine tools have been developed to implement several mechanical machining operations on one machine in order to rapidly and economically fabricate those components/products while research has also been drawn on the development of hybrid machines which will integrate conventional and non-conventional machining processes on them [9]. Some hybrid micro-machining processes have been approved to be able to improve machinability of hard-to-machine materials, tool life, geometrical accuracy, surface integrity and machining efficiency.

There is no exact description for hybrid machining processes [10]. From time to time a number of definitions for hybrid machining processes have been proposed by researchers like Rajurkar et al. [11], Kozak and Rajurkar [12], Aspinwall et al. [13], Curtis et al. [14], Lauwers [15] etc.. Aspinwall et al. [13] explained that the combination of machining operations can be considered either in terms of a hybrid machining method, by which two or more machining processes are applied independently on a single machine, or in terms of an assisted machining approach, by which two or more processes are utilised simultaneously. She and Hung [16] stated that hybrid machines can perform different operations such as mechanical milling and turning at one place. Curtis et al. [14] provided a narrow definition, stating that only a method, where two or more material removal processes work simultaneously can be termed as 'hybrid'. In 2014, the College International Pour la Recherche en Productique (CIRP) collaborative working group on hybrid processes put forward the following definition: hybrid machining processes are based on the simultaneous and controlled interaction of machining mechanisms and/or energy sources/tools having a 
significant effect on the process performance. The wording "simultaneous and controlled interaction" means that the processes/energy sources should interact more or less in the same processing zone and at the same time [17]. Accordingly, in this paper, hybrid micromachining processes are classified as assisted and combined hybrid micro-machining processes (as shown in Fig. 1). The major part of the paper (sections 2 and 3) provides a comprehensive review on the state-of-the-art hybrid micro-machining researches conducted within the above categories. Section 4 discusses the case studies on integration of hybrid micro-machining with other micro-machining and assisted techniques. Future research opportunities in hybrid micro-machining processes are discussed in section 5. The paper will conclude with a brief review on the discussed subjects. In the paper micro-machining processes refer to mask-less direct material removal processes. It should be noted here that hybrid surface and bulk micro-machining based on coating, lithography, moulding, etching and assembly of films and substrates are other approaches that will not be covered in the paper. 


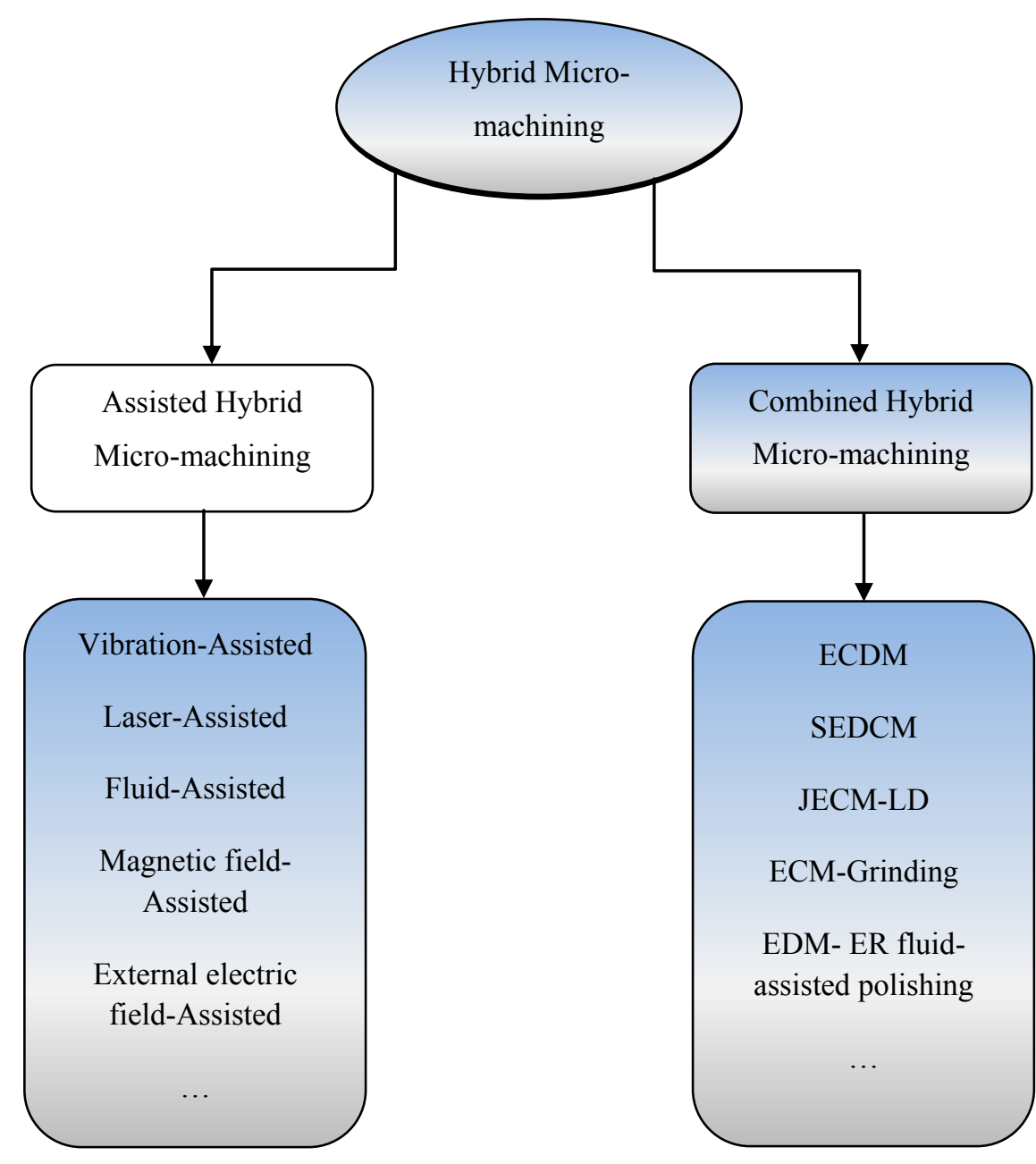

Fig. 1. Classification of hybrid micro-machining processes

\section{Assisted hybrid micro-machining processes}

For assisted hybrid micro-machining, the major machining process is superimposed with input from one or several types of energy such as ultrasonic vibration, laser, fluid, magnetic field etc. so as to improve the constituent micro-machining process [15, 18]. 


\subsection{Vibration assisted micro-machining}

Vibration-assisted micro-machining combines precision micro-machining with smallamplitude tool, workpiece or work fluid vibrations. This approach has been applied to a number of processes from micro-milling to micro-electrochemical discharge machining (ECDM). During vibration-assisted micro-cutting, the cutting tool loses contact with the chips on specified amplitude, resulting in decreasing of machining forces and improving tool life and surface finish [19]. However, it may result in surface cracks due to the hammering of the tool [15].

Vibration also finds its applications in other non-cutting processes. For example, in ultrasonic-assisted electrodischarge micro-machining (EDM), vibration can be applied between the tool and workpiece in order to increase the flushing efficiency, resulting in a higher material removal rate. If process parameters are selected carefully, smooth surfaces can be obtained. The vibration supports the removal of re-solidified debris and hence results in a smaller heat-affected zone (HAZ), lower thermal stresses and fewer cracks [15]. Besides, work fluid vibration heightens circulation of the debris and increases the machining rate, surface finish and accuracy in processes such as micro-EDM and electrochemical machining (ECM). A summary of research work carried out in this area is listed in Table 1.

Table 1. Summary of the vibration-assisted micro-machining processes

\begin{tabular}{|c|c|c|}
\hline $\begin{array}{c}\text { Vibration-assisted micro- } \\
\text { machining process }\end{array}$ & Work material & Primary characteristic \\
\hline Vibration-assisted milling & $\mathrm{H} 13$ [22], Al 6061 [51-52], AL6061-T6 [49] & Achieved surface roughness (Ra) for \\
& & AL6061 is 0.105 $\mu \mathrm{m}[52]$ \\
\hline
\end{tabular}




\begin{tabular}{|c|c|c|}
\hline & & Nearly $22 \%$ reduction in tool life [49] \\
\hline Vibration-assisted grooving & $\begin{array}{l}\text { Glass [25,32], Al2024 [26], Plexiglas [26], } \\
\text { Brass [28], Si wafer [33], Pure nickel [27], } \\
\text { Nickel alloy [27], Mold steels [27], Al6061 } \\
\text { [27], Copper [29-30] }\end{array}$ & $\begin{array}{l}\text { Better micro-groove shape }[25,27] \\
\text { Reduction in average size of chippings } \\
\text { [32] }\end{array}$ \\
\hline Vibration-assisted engraving & $\begin{array}{c}\text { Aluminium alloy [32], Piezoceramic } \\
\text { material [32], Stainless steel [32] }\end{array}$ & $60 \%$ reduction in cutting force [32] \\
\hline Vibration-assisted grinding & Ultra-fine grain cemented carbide [24] & $\begin{array}{c}10-20 \% \text { smaller diameter and } 50 \% \\
\text { higher aspect ratio when fabricating of } \\
\text { micro-tools [24] }\end{array}$ \\
\hline Vibration-assisted drilling & $\begin{array}{c}\text { Single crystalline silicon [23], Glass [53], } \\
\text { AA2017 [54], SUS304 [54], Al6061-T6 } \\
\text { [50], SS41 [50] }\end{array}$ & $60-70 \%$ reduction in cutting force [53] \\
\hline Vibration-assisted polishing & Binderless tungsten carbide [36-38] & $\begin{array}{l}\text { Achieved surface roughnesses are } 7 \mathrm{~nm} \\
\text { Ry [36], } 8 \mathrm{~nm} \mathrm{Rz} \mathrm{[37],} 12 \mathrm{~nm} \mathrm{Rz} \mathrm{[38]}\end{array}$ \\
\hline Vibration-assisted lapping & Silicon [34], Ti-6Al-4V [55] & $\begin{array}{l}\text { Achieved surface roughness (Ra) for } \\
\text { Silicon is } 10 \mathrm{~nm}[34]\end{array}$ \\
\hline Vibration-assisted EDM & $\begin{array}{l}\text { Stainless steel [56, 64], Copper [56], A2 tool } \\
\text { steel [65], 1.5920 steel [63], WC of Grade } \\
\text { MG18 [57-61], Steel [62], X210Cr12 (D3 } \\
\text { DIN) [42], SUS304 [72, 73-74], } \\
\text { Polycrystalline diamond [40], Nitinol [41], } \\
\text { Hymu } 80 \text { [62], Brass [39] }\end{array}$ & $\begin{array}{l}\text { Up to } 66.48 \% \text { increasing of material } \\
\text { removal rate [40] } \\
\text { Increasing the machining efficiency by } \\
\text { more than } 60 \text { times [41] }\end{array}$ \\
\hline Vibration-assisted EDM milling & Red copper [66] & $\begin{array}{c}6.5 \text { times improvement in machining } \\
\text { efficiency [66] }\end{array}$ \\
\hline
\end{tabular}




\begin{tabular}{|c|c|c|}
\hline Vibration-assisted reverse EDM & Ti-6Al-4V [44] & Improvement in process stability [44] \\
\hline Vibration-assisted WEDM & Ti-6Al-4V [67], Tungsten carbide [43] & 2.5 times increase in machining \\
efficiency [67]
\end{tabular}

\subsubsection{Tool vibration-assisted micro-machining}

In tool vibration-assisted micro-machining, a piezoelectric transducer, booster and horn are usually applied to generate tool vibration. Electrical impulses are fed to a piezoelectric transducer and transformed into mechanical vibrations of ultrasonic frequency thanks to the piezoelectric effect. The vibration amplitude is then amplified by the booster and the horn and transmitted to the tool attached to the horn [20-21]. The primary focus in tool vibrationassisted micro-machining is on the study of the vibration effect on the tool wear, surface quality, micro-cutting forces, material removal rate (MRR), machining time, micro-hole aspect ratio and chipping. This has been performed by fabrication of simple micro-structures like micro-grooves and holes on different materials with main purpose of investigation of the processing parameters.

Ultrasonic vibration-assisted micro-milling, grinding, drilling and grooving are found to have the ability to produce better geometrical shape, surface quality, lower tool wear and chipping [22-25]. Fig. 2 shows a machining system of the ultrasonic vibration-assisted micro-grooving used for grooving of glass and planar lightwave circuits. 


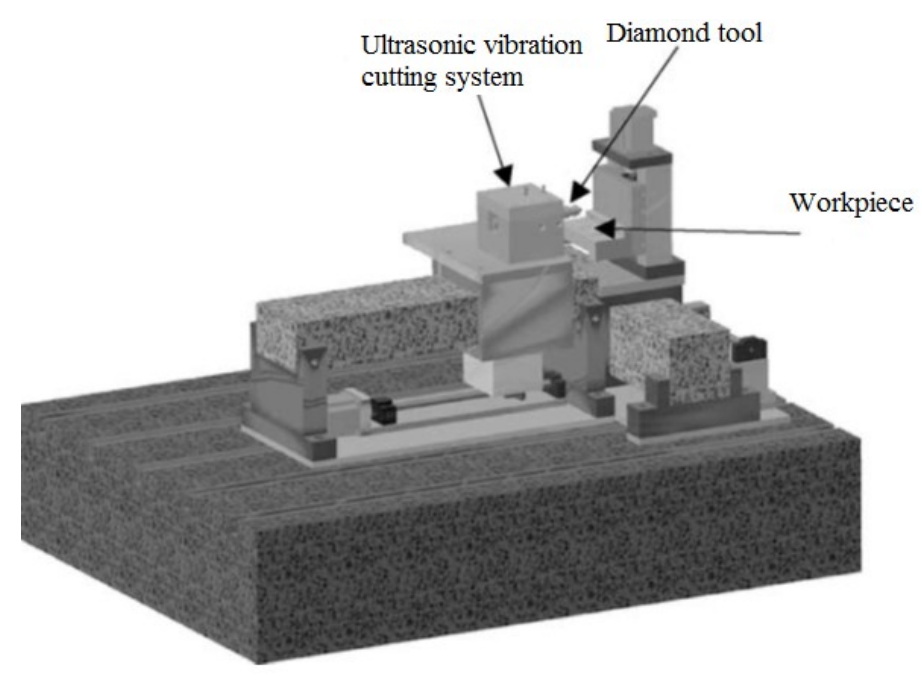

Fig. 2. Schematic of ultrasonic vibration-assisted micro-grooving [25]

Ultrasonic vibration-assisted micro-machining can be performed by elliptical vibrations [2630]. A two-dimensional elliptical cutting path can be created at the cutting tool with out-ofphase synchronous excitations of the cutting tool in the cutting and thrust directions. Cutting along the elliptical tool path is termed as 2-dimensional-vibration-assisted cutting or elliptical-vibration-cutting (EVC). The improvement compared to conventional cutting method $(\mathrm{CCM})$ is very clear when machining with a worn cutting tool as shown in Fig. 3. However, the risk of catastrophic or fatigue failure of tool is increased by the impulsive forces resulting from the periodic contact between the tool and workpiece. The consequence of EVC can be explained as decrease of cutting resistance and improvement of machined surface finish due to increased reverse frictional force between the tool and chip. 

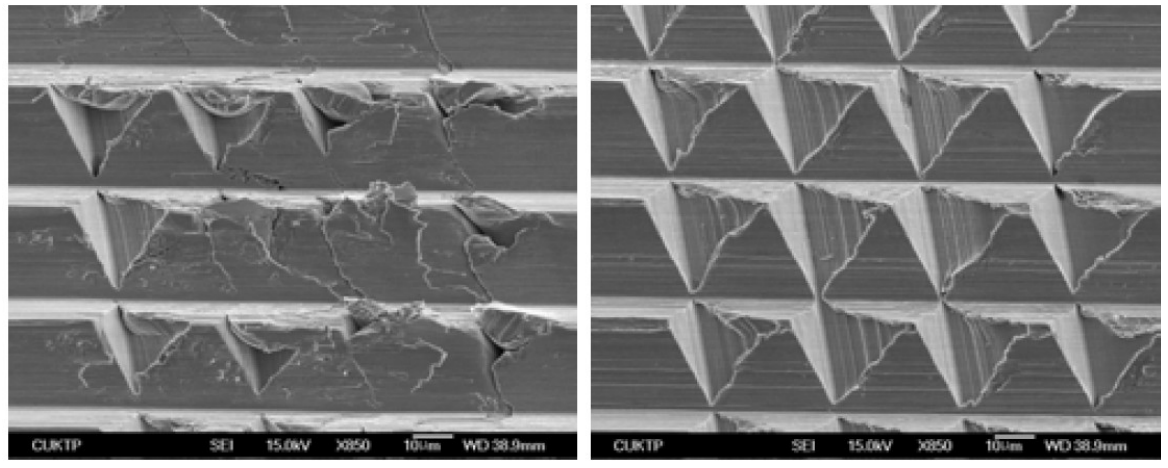

Fig. 3. Comparisons of pyramid patterns machined by CCM and EVC (workpiece material: Inconel 600) [27]

Ultrasonic elliptical vibration transducer can be integrated with fast tool servo (FTS) to realize complex shape machined surfaces while achieving reduced cutting force and prolonged tool life [31]. $60 \%$ reduction of cutting force is observed in the cutting process with this new vibration device. Two dimensional error curve of micro-V-groove machined on aluminium alloy (shown in Fig. 4) indicates that there is a significant degradation of the machined shape with a large increase of the error when micro-V-grooving with vibration assistance.

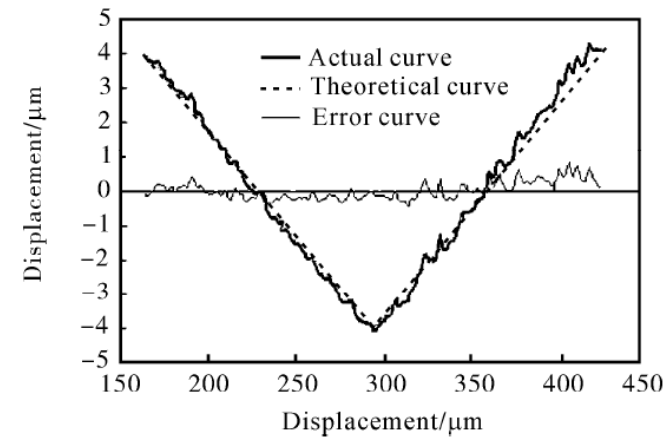

(a) Machined without vibration

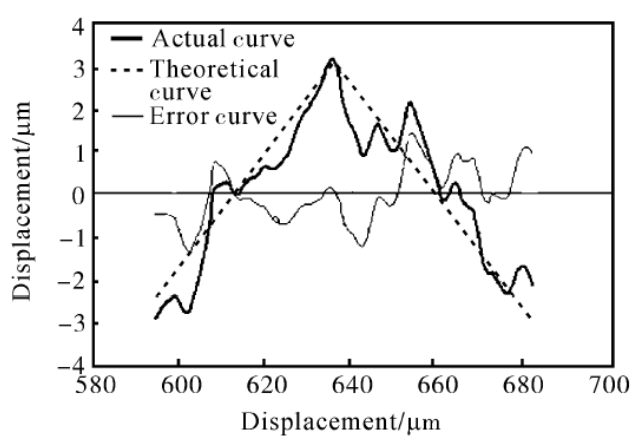

(b) Machined with vibration 
Fig. 4. Two-dimensional error curve of micro-V-groove surface on aluminium alloy workpiece [31]

Ultrasonic-assisted micro-lapping has the ability to make hole arrays, trenches, rings, polygons, asterisks, spirals, arbitrary curves, etc., on silicon with feature sizes ranging from 50 to $500 \mu \mathrm{m}$, and aspect ratios of from 1 to 5 [34]. However, it is claimed that the currently available knowledge on ultrasonic-assisted micro-lapping is still insufficient especially on tool wear, subsurface damage control, and relatively coarse surface roughness [35].

In polishing of micro-aspheric molds, an ultrasonic vibration assisted polishing tool is useful to finish the surface. A small polishing tool (shown in Fig. 5) is mounted on a three-axis or five-axis controlled work table, and vibrated at an ultrasonic frequency by piezoelectric actuators, as illustrated in Fig. 6. Application of this polishing machine on tungsten carbide results in lowering surface roughness to $8 \mathrm{~nm} \mathrm{Rz} \mathrm{[36-38].}$

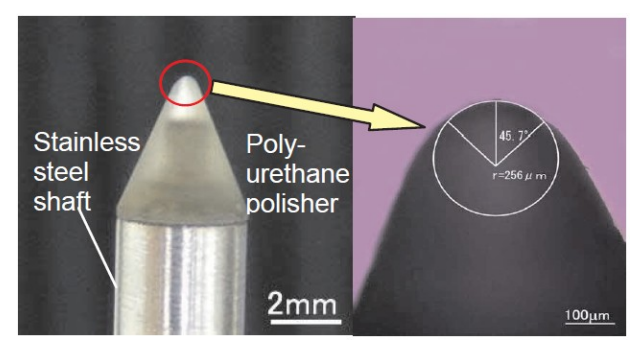

Fig. 5. View of polishing tool [36] 


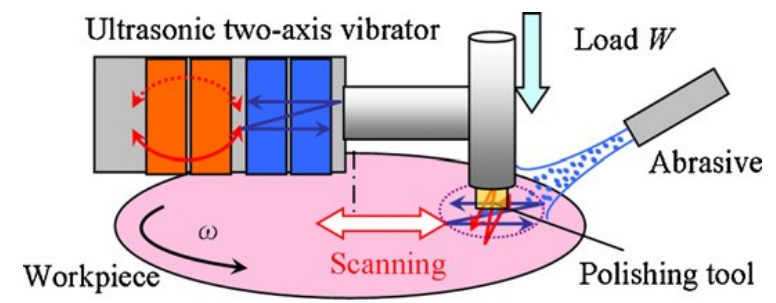

Fig. 6. Illustration of ultrasonic two-axis vibration-assisted polishing [37]

Adding ultrasonic vibration to non-traditional micro-machining processes allows an improvement in machining performance. The combination of tool vibration and EDM has profound effects on reduction of machining time and increasing machining stability without increasing surface roughness and tool electrode wear [39-41]. It is found that the perpendicular vibration has a shorter machining time than the parallel vibration in vibrationassisted micro-EDM process [39]. Based on both experimental data and finite element method (FEM) modelling results, It is confirmed that when using longer pulse time $(25 \mu \mathrm{s})$ the advantage of tool ultrasonic vibration-aided micro-EDM of X210Cr12 (D3 DIN) is more apparent in terms of machining rate. But longer pulse time than $25 \mu \mathrm{s}$ is not appropriate at usual $20 \mathrm{kHz}$ frequency since higher pulse energy will result in low machining accuracy and surface quality [42]. In wire electrical discharge grinding (WEDG), by adding vibration to the wire electrode directly, the surface integrity of tungsten carbide can be improved which is superior to that by vibrating dielectric fluid or without ultrasonic assistance [43].

Fig. 7 shows a schematic illustration of vibration-assisted reverse micro-electrical discharge machining (R-MEDM) which is used to create micro-pillars of $40-50 \mu \mathrm{m}$ diameter. It is claimed that a surface texture comprising of any cross-section micro-pillar array on the metallic surfaces can be produced deterministically only by the R-MEDM process [44]. 


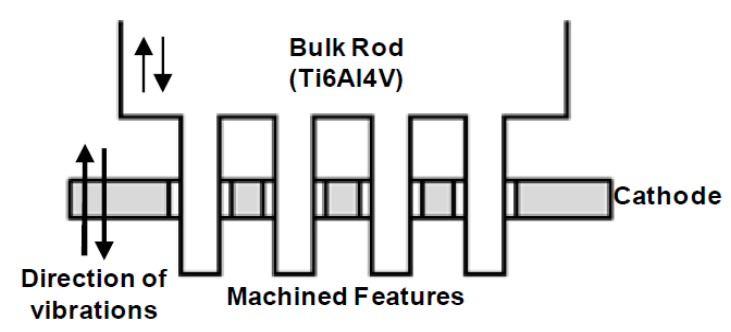

Fig. 7. Vibration-assisted R-MEDM [44]

Integration of the electrochemical micro-machining (EMM) with tool vibration has been used for decreasing surface roughness [45]. When micro-drilling of thin copper workpiece by using this process, the $150-200 \mathrm{~Hz}$ range of tool vibration frequency is recommended, which provides a better electrochemical machining in the narrow end gap [46]. Besides, it is suggested that EMM of SS304 should be conducted at low amplitude of vibration of microtool and medium frequency to get more cylindrical micro-borehole with lesser overcut and with better surface finish [47-48].

\subsubsection{Workpiece vibration-assisted micro-machining}

For workpiece vibration, piezoelectric transducers, boosters and horns are employed to cause the workpiece material to vibrate by converting frequency oscillation electric power into mechanical vibration. The research focus in workpiece vibration-assisted micro-machining is on creating simple shapes to explore the influence of vibration on the tool life, surface quality, dimensional accuracy, micro-cutting forces, MRR and micro-hole aspect ratio.

It is found that the average overside and positioning error are decreased and surface roughness and tool life are improved during workpiece 2D (elliptical) vibration-assisted micro-milling and drilling of AL6061-T6 [49-50]. The amplitude of the ultrasonic vibration 
is an important parameter that can be optimized to achieve good surface roughness in this process [51]. Reduction in force and increase of tool life, machining rate and machinable depth are observed during workpiece vibration-assisted micro-drilling of glass [53], AA2017 (duralumin) and SUS304 [54]. This reduction in force can be achieved by $60-70 \%$ [53]. To produce high precision micro-holes, workpiece vibration-assisted micro-lapping (as illustrated in Fig. 8) is employed in order to improve the surface roughness and the roundness of micro-holes [55].

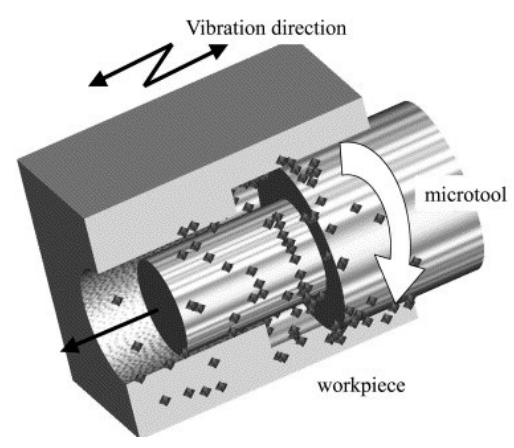

Fig. 8. Using the stepped circular tool to manufacture the micro-hole in the vibration-assisted micro-lapping process [55]

Workpiece vibration-assisted micro-EDM has been successfully performed by different researchers. In the experiments carried out by Gao and Liu [56] ultrasonic vibration actuator was adhered to the workpiece in micro-EDM, which led to eight times efficiency improvement. Fig. 9 shows the experimental apparatus used by Gao and Liu [56]. 


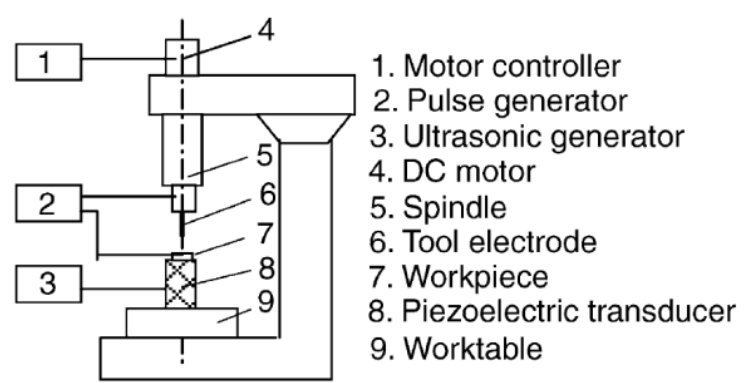

Fig. 9. The combined apparatus of ultrasonic and micro-EDM [56]

It is revealed that there is a significant improvement in dimensional accuracy, surface quality and MRR with substantial reduction of EDM gap, machining time and electrode wear rate (EWR) during drilling deep micro-holes by means of workpiece vibration-assisted microEDM. The experimental results also disclose that the low frequency vibration is more effective at the low discharge energy level, thus making it more suitable for micro-EDM [5761]. Other studies employing workpiece vibration-assisted micro-EDM have been reported [62-65]. Fig. 10 shows the SEM (scanning electron microscope) photographs of a machined 3D micro-structure by using workpiece vibration-assisted servo scanning 3D micro-EDM [66].

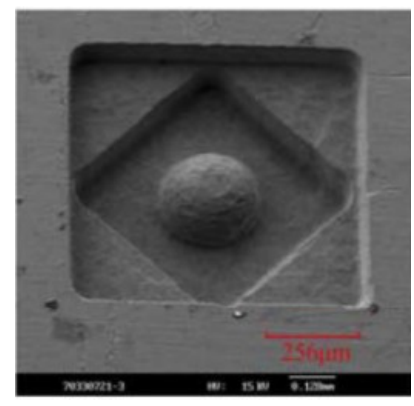

Fig. 10. Machined 3D micro-structures by workpiece vibration-assisted servo scanning 3D micro-EDM (workpiece material: Red copper) [66] 
As identified by Hoang and Yang [67], greater improvement can be achieved when the vibration is applied to the workpiece rather than to the wire in micro-wire electrodischarge machining (WEDM) of Ti-6Al-4V. With vibration applied to the workpiece, the machining efficiency can be increased by 2.5 times of that without vibration and 1.5 times compared to the case when vibration is applied to the wire.

Applying vibration to the workpiece during laser micro-machining would deactivate the agglomeration of nanoparticles and prevent the surface oxidation and the formation of recast layer. Fig. 11 depicts the concept of this process. As a result, the surface roughness of a machined surface could be more improved in the ultrasonic vibration-assisted laser micromachining than that in the case without vibration assistance [69-70].
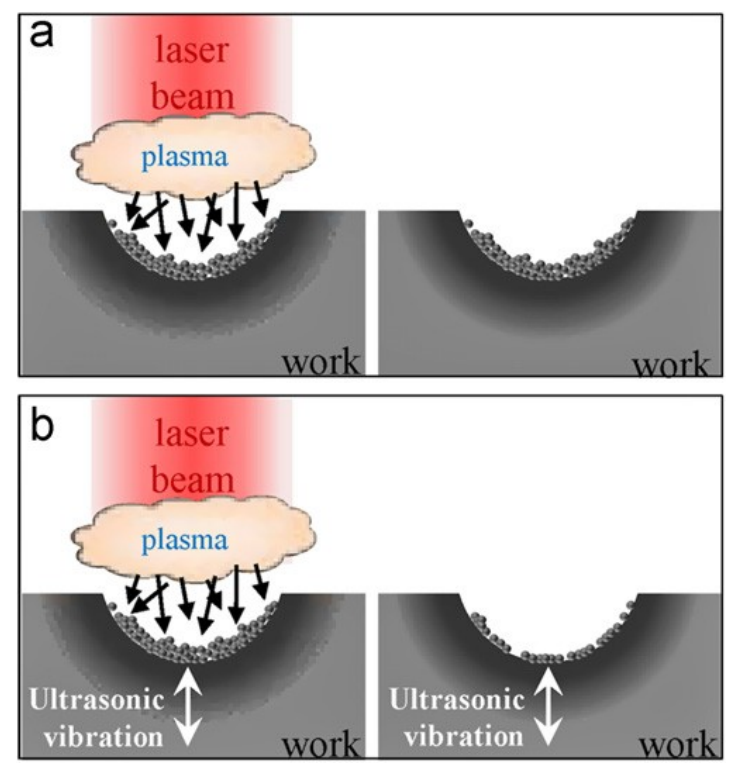

Fig. 11. Concept of laser ablation processes by (a) conventional method and

(b) ultrasonic-applied method [69] 


\subsubsection{Work fluid vibration-assisted micro-machining}

To vibrate the work fluid, an ultrasonic transducer is usually attached to the work tank. Work fluid vibration is an effective way to circulate debris and increase material removal rate and geometrical accuracy in micro-EDM [71-72]. A schematic of the experimental system of the work fluid vibration-assisted micro-EDM is presented in Fig. 12 [72]. Work fluid vibration can be realized by applying a horn [73-74]. In the horn tip there is a small circular hole. Since the tool electrode is fed through this hole, ultrasonic vibration can be applied to machining fluid without the contact between the tool electrode and the vibrating horn. Higher machining speed, shorter lateral gap width between the tool electrode and workpiece, and smaller discharge energy and tool wear rate are the results of using such horn.

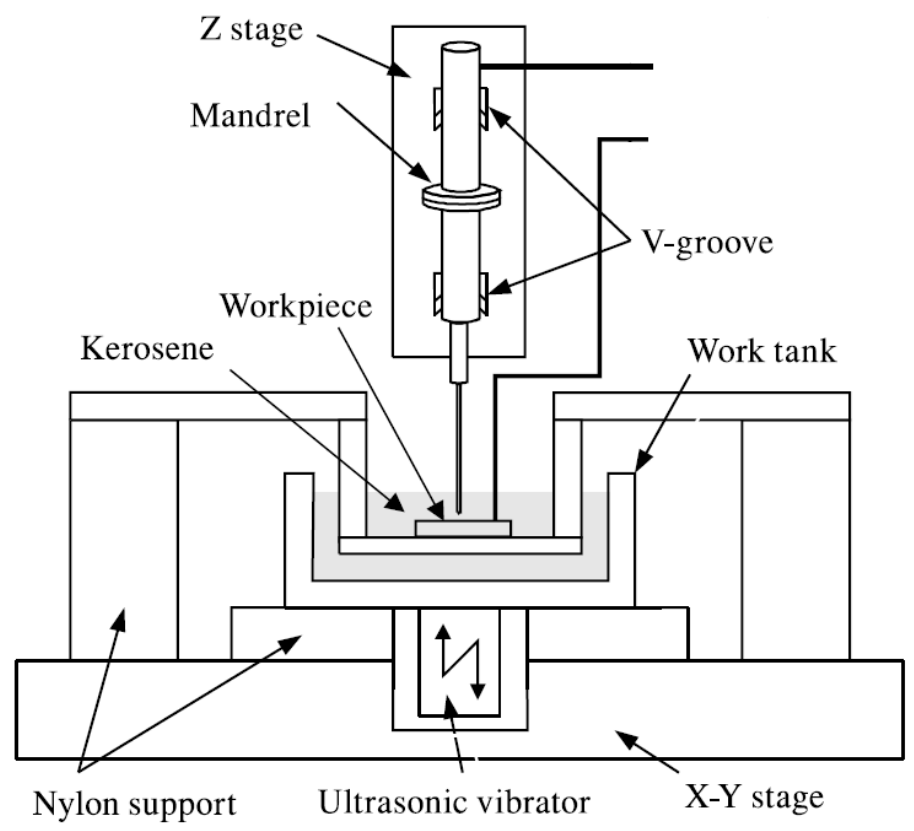

Fig. 12. Schematic diagram of the work fluid vibration-assisted micro-EDM [72]

\subsubsection{Objective lens vibration-assisted micro-machining}


In 2012, the effectiveness of vibration of an objective lens in vibration-assisted femtosecond laser micro-drilling of copper substrate was investigated by Park et al. [75-76] as shown in Fig. 13. It was found that both the wall surface finish of the machined structures and the aspect ratio have been improved. This is attributed to a stirring effect stemming from vibration of the objective lens (or focused beam point), which enhances the heat transfer of the ablated particles due to local force convection. The increased cooling helps reduce the probability of particles being joined to the wall surfaces and particle agglomeration. As a result, the wall surface appears much cleaner than those obtaining by conventional laser micro-drilling. Furthermore, the aspect ratio was increased by $154 \%$ compared with no vibration.

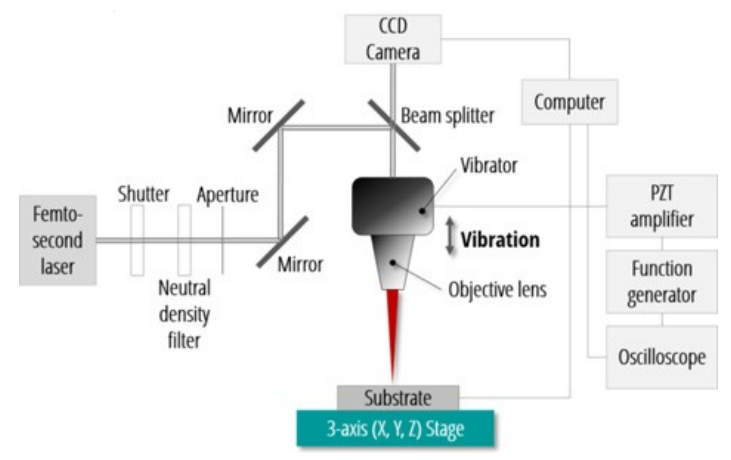

Fig. 13. Schematic diagram of vibration-assisted femtosecond laser micro-drilling system [77]

\subsection{Laser-assisted micro-machining}

High strength and heat resistant materials are often difficult to machine due to their physical and mechanical properties such as high strength and low thermal conductivity, which make the cutting forces and cutting temperature very high and lead to a short tool life. Because the 
flow stress and strain hardening rate of materials normally decrease with the increase of temperature due to thermal softening, thermal-assisted machining becomes a possibility when machining the hard-to-machine materials (see Fig. 14) [78]. Table 2 gives an overview of the performed studies on the laser-assisted micro-machining processes. The major work on laserassisted micro-machining is to study some parameters such as surface roughness and micromachining forces by manufacturing simple micro-grooves and then to compare with those obtained by conventional micro-machining.

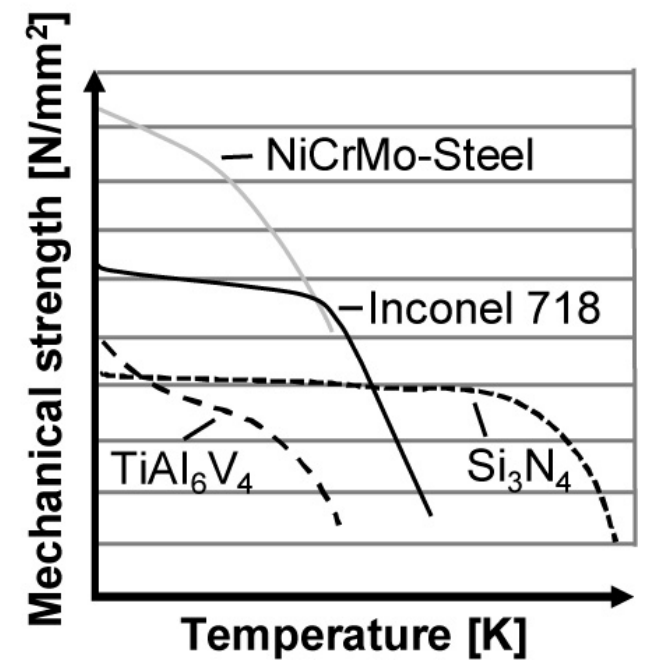

Fig. 14. Mechanical strength as a function of temperature [17]

Table 2 Overview of the studies on the laser-assisted micro-machining

\begin{tabular}{|c|c|c|}
\hline $\begin{array}{c}\text { Laser-assisted micro- } \\
\text { machining process }\end{array}$ & Work material & Primary characteristic \\
\hline Laser-assisted milling & H13 [79-81], A2 tool & 17\% reduction in mean thrust force [79-81] \\
& steel [82-86], Ti-6Al-4V & 69\% reduction in peak resultant force [88-91] \\
& {$[88-91]$, Inconel 718 } & \\
\hline
\end{tabular}




\begin{tabular}{|c|c|c|}
\hline & $\begin{array}{c}\text { [88], AISI } 422 \text { [88], AISI } \\
\text { D2 [89-91] }\end{array}$ & $\begin{array}{l}\text { Improvement in accuracy of groove depth [79-81] } \\
\text { Increase of material removal rates up to six times [88-91] } \\
\text { Achieved surface roughness (Sa) for H13 is } 0.65 \mu \mathrm{m} \text { [79- } \\
\qquad 81] \\
\text { Achieved surface roughness (Ra) for A2 is nearly } 0.1 \\
\qquad \mu \mathrm{m}[83-86]\end{array}$ \\
\hline Laser-assisted grinding & $\begin{array}{l}\text { Reaction-sintered silicon } \\
\text { nitride [83-85], } \mathrm{Si}_{3} \mathrm{~N}_{4} \\
\text { [92], } \mathrm{Al}_{2} \mathrm{O}_{3}[92]\end{array}$ & $\begin{array}{l}\text { Up to } 43 \% \text { reduction in average grinding forces [83-85] } \\
\text { Achieved surface roughness (Ra) for } \mathrm{Si}_{3} \mathrm{~N}_{4} \text { is } 112.85 \mathrm{~nm} \\
\qquad[92]\end{array}$ \\
\hline Laser-assisted scratching & $4 \mathrm{H}-\mathrm{SiC}[82]$ & Greater than $50 \%$ reduction in hardness [82] \\
\hline Laser-assisted jet ECM & $\begin{array}{c}\text { Aluminium alloy, } \\
\text { Titanium alloy, Hastelloy } \\
\text { and, Stainless steel } \\
{[93-96]}\end{array}$ & $\begin{array}{l}\text { Up to } 78 \% \text {. reduction in hole taper } \\
\text { Up to } 46 \% \text { increase in material removal rate } \\
\text { [93-96] }\end{array}$ \\
\hline $\begin{array}{l}\text { Laser-assisted water jet } \\
\text { machining }\end{array}$ & $\begin{array}{l}\text { Single crystalline silicon } \\
\qquad[97-98]\end{array}$ & Near free of HAZ and high material removal rate [97-98] \\
\hline
\end{tabular}

\subsubsection{Laser-assisted micro-milling/grinding}

During laser-assisted micro-milling/grinding, workpiece is heated by a low power continuous wave fibre laser and therefore is thermally softened. Laser provides intense localized heating to the workpiece ahead of the cutting region. In this way the strength of the workpiece is reduced and its machinability is improved. A schematic view of this process is illustrated in Fig. 15. Laser-assisted micro-milling/grinding can result in decreased machining forces and 
improved machining accuracy and machined surface finish. However, cracks will appear in the zone adjacent to the cutting zone (normally is called as HAZ). The density of the cracks increases with the increase of temperature [15]. Besides, this high temperature may lead to shorter tool life due to the premature degradation of the cutting tool and accelerated dissolution-diffusion and adhesion wear [78].

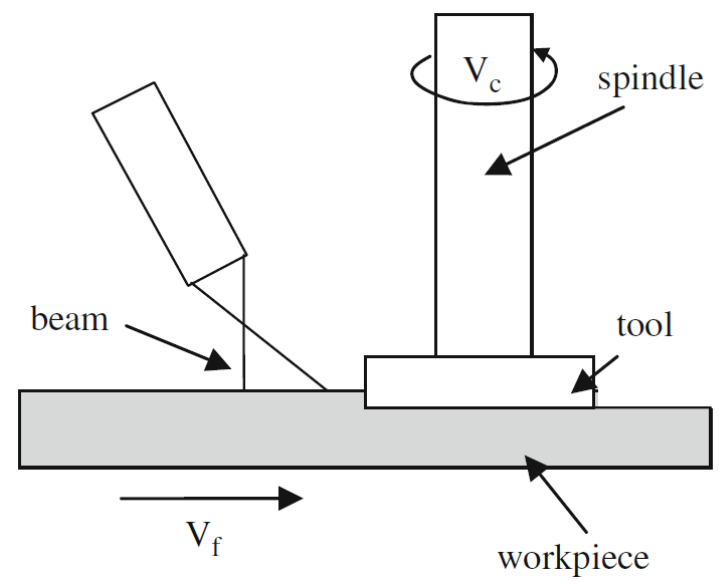

Fig. 15. Schematic view of laser-assisted milling [78]

Laser variables significantly influence the process response. Specifically, the mean thrust force is found to decrease by $17 \%$ and the $3 \mathrm{D}$ average surface roughness increases by $36 \%$ when the laser power is increased from 0 to $10 \mathrm{~W}$ in laser-assisted micro-machining of H13 steel. For different nominal depths of cut with and without laser heating, the dimensional accuracy of the groove depth increases appreciably with laser heating. If the temperature in the material removal region is below the critical range $\left(840-890{ }^{\circ} \mathrm{C}\right)$ then there will be no residual HAZ in the material after micro-cutting [79-81]. Decreased peak resultant force and tool wear, more accurate groove geometries, increased material removal rates (even up to six times) for the hard metals such as A2 tool steel and reaction-sintered silicon nitride have also 
been reported in laser-assisted micro-machining [83-86]. However, in laser-assisted microgrinding of $\mathrm{Si}_{3} \mathrm{~N}_{4}$ and $\mathrm{Al}_{2} \mathrm{O}_{3}$, grinding depth and force are almost the same as those in conventional micro-grinding process [92]. The disadvantage of laser-assisted micromachining is that burr heights increase due to thermal softening of the workpiece. When a tool diameter larger than the laser spot size is employed, the increase in burr height is much smaller. When the laser spot size is larger than the tool diameter, the surface roughness is found to increase due to increased thermal softening of the material [83].

There are a few research papers reporting on FEM modelling of laser-assisted micro-milling (LAMM). This is partly because the available flow stress models are independent of the length scale in the FE simulation and hence are not suitable for describing the significant size effect in micro-cutting. In the researches, chip formation, flow stresses, temperature distribution and velocity fields, which relate to the surface integrity analysis and built-up edge (BUE) formation in micro-milling have been investigated [87-91].

\subsubsection{Laser-assisted jet electrochemical micro-machining}

In laser-assisted jet electrochemical machining (LAJECM), the main objective of employing a laser is to improve the precision by better process localisation. Fig. 16 schematically illustrates the principles and the mechanisms of LAJECM. The laser (power density $47.5 \mathrm{~W} / \mathrm{mm}^{2}$ ) is used only to thermally activate the outer surface layer. The predominant mechanism of material removal is electrochemical dissolution and the role of the laser is to assist and direct the electrochemical energy. The thermal energy of the laser transmitted to the workpiece enhances the kinetics of electrochemical reactions and hence enables the localisation of dissolution to a specific area. Laser-workpiece and laser-electrolyte interaction cause higher material removal rate in axial rather than in the lateral direction and thereby 
dimensional precision is improved. In addition to the localisation effect, the laser beam aids in the removal of surface oxide layers that form on materials, thus enabling electrochemical machining of materials such as titanium without recourse to hazardous electrolytes. Fig. 17 summarises the aspects laser localisation effects on jet ECM. The precision and productivity improvements of LAJECM compared to jet electrochemical machining (JECM) have been evidenced by experiments on aluminium alloy, titanium alloy, Hastelloy and stainless steel. LAJECM can effectively facilitate material removal of 20, 25, 33, and 54\% for Hasteloy, titanium alloy, stainless steel and aluminium alloy, respectively. There is also a noticeable improvement in the shape accuracy and slight decrease in surface roughness of the holes and cavities produced due to more focused machining (the order of $20 \%$ ). The measured reduction in taper is of the order of $38,40,41,65 \%$ for aluminium alloy, stainless steel, Hasteloy and titanium alloy, respectively [93-96].

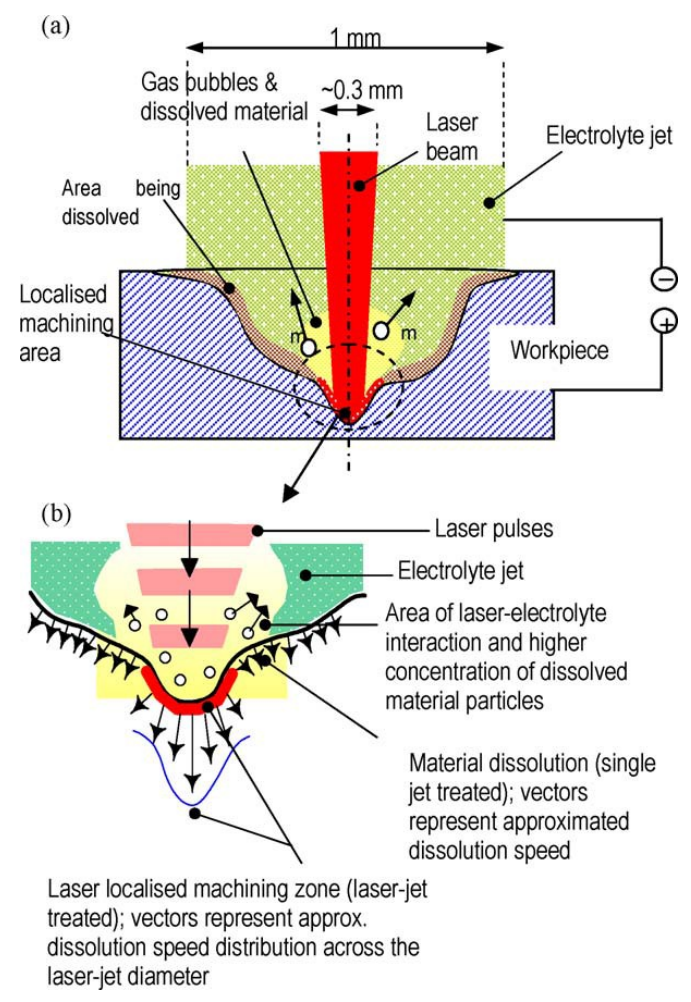


Fig. 16. Laser-assisted jet electrochemical machining process: (a) general view and (b) laser localised machining area [95]

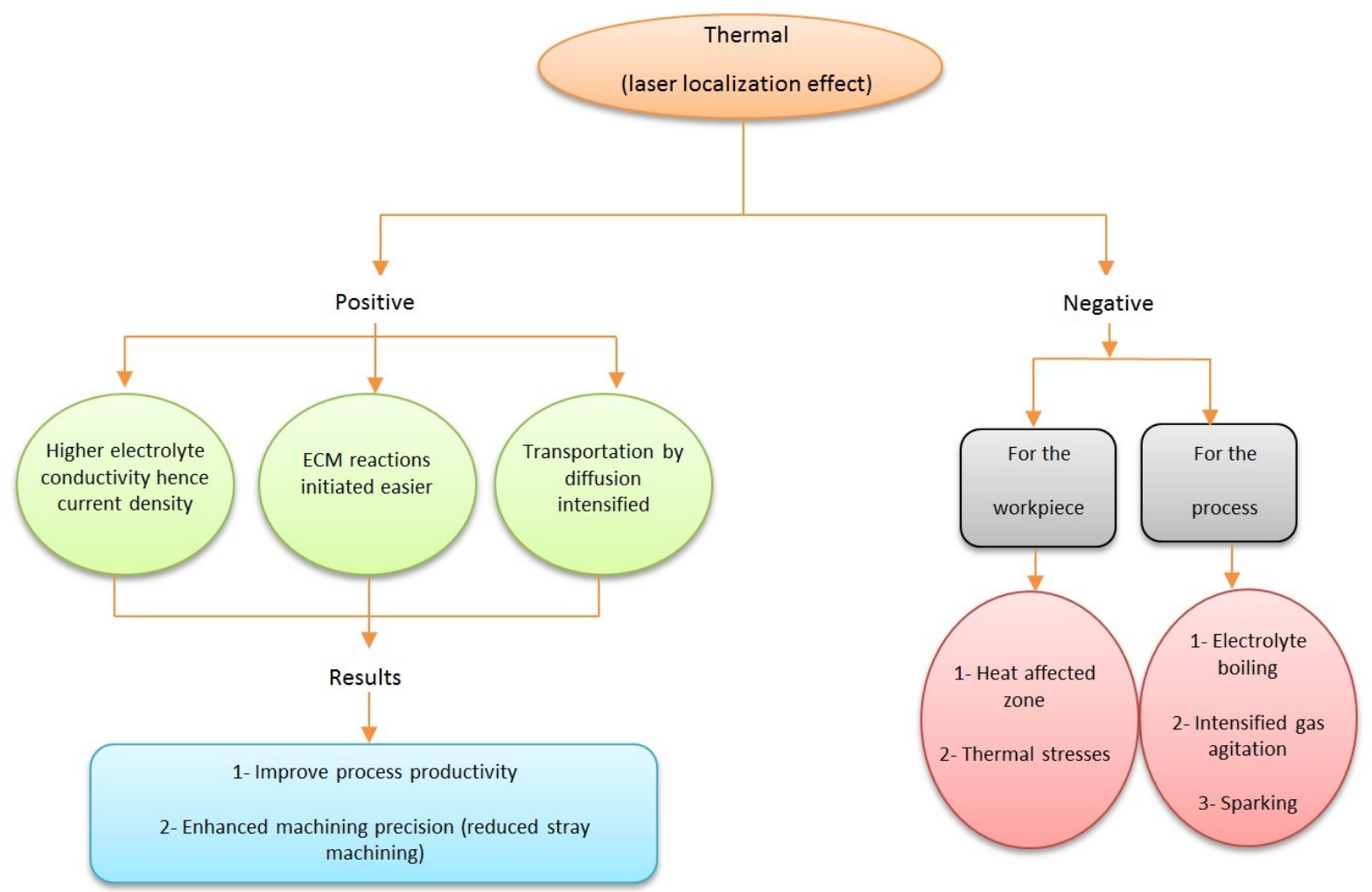

Fig. 17. Aspects of laser-electrolyte jet interaction in LAJECM (Redrawn from reference [95])

\subsubsection{Laser-assisted water jet micro-machining}

The fundamental of this hybrid micro-machining technology is that, rather than achieving material removal through melting and vaporizing the material by lasers, elemental material is heated and softened by laser heating and removed by the expulsion of a high pressure waterjet. This will not only reduce the temperature for material removal so as to reduce thermal damages, but also requires less thermal energy input that allows the laser traverse 
speed to be increased for a high cutting rate. Further, the cooling action by the waterjet reduces thermal effect on the workpiece. It is believed that the pulsed laser heating and waterjet expelling process also involves thermal shock effect on the work material, which may result in micro-crack-induced material removal. However, it is believed that with a suitable pressure setting of the waterjet, the contribution of this thermal shock to material removal is minimum. To enable the waterjet to expel and remove the laser-softened elemental material, the waterjet and laser beam have to be moved simultaneously during the traverse motion. For this purpose, a hybrid laser-waterjet cutting head is developed, as shown in Fig. 18. The waterjet nozzle is incorporated into a laser cutting head by placing the waterjet sideby-side with the laser beam. It has been found that almost no HAZ with a higher material removal rate can be achieved when using this hybrid laser-waterjet technology, as compared to the conventional laser dry micro-machining process [97-98].

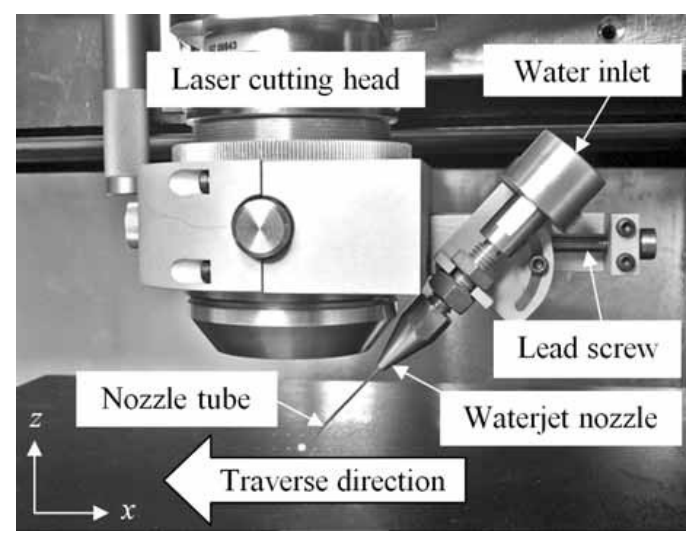

Fig. 18. The hybrid laser-assisted waterjet cutting head [97-98]

\subsection{Fluid-assisted micro-machining}


This hybrid assisted micro-machining process includes applying water, gas, chemicals or special fluids on the workpiece with the aim of increasing the process performance. Table 3 gives an overview of the micro-machining processes carried out with the assistance of various fluids.

Table 3. Summary of the fluid-assisted micro-machining processes

\begin{tabular}{|c|c|c|}
\hline $\begin{array}{l}\text { Fluid-assisted micro-machining } \\
\text { process }\end{array}$ & Work material & Primary characteristic \\
\hline water-assisted laser machining & $\begin{array}{c}\text { Silicon [99], LCD glass } \\
\text { [101], alumina [104], } \\
\text { PET [104], PMMA [104] }\end{array}$ & $\begin{array}{l}\text { Increase of material removal rates up to twice [99] } \\
\text { Improvement in surface quality [104] } \\
\text { No laser ablation enhancement for PET [104] } \\
\text { Reduction in micro-cracking and HAZ size [101] }\end{array}$ \\
\hline Gas-assisted laser drilling & $\begin{array}{l}\text { Nimonic } 263 \text { coated with } \\
\text { a TBC }[105]\end{array}$ & Delamination-free drilled holes [105] \\
\hline $\begin{array}{l}\text { Methanol-assisted laser } \\
\text { machining }\end{array}$ & $\begin{array}{l}\text { Single crystalline silicon } \\
\text { carbide }[106]\end{array}$ & Improvement in drilling quality [106] \\
\hline $\begin{array}{l}\text { Salt solution-assisted laser } \\
\text { machining }\end{array}$ & 316 stainless steel [107] & Up to $300 \%$ increase in material removal rate [107] \\
\hline $\begin{array}{l}\text { Chemical-assisted ultrasonic } \\
\text { machining }\end{array}$ & Glass [108] & $\begin{array}{l}\text { Up to } 40 \% \text { improvement in surface finish and material } \\
\text { removal rate }[108]\end{array}$ \\
\hline $\begin{array}{l}\text { Electrochemical-assisted } \\
\text { machining }\end{array}$ & 304 stainless steel [109] & Decrease cutting force [109] \\
\hline
\end{tabular}




\begin{tabular}{|c|c|c|}
\hline $\begin{array}{c}\text { Electrorheological fluid-assisted } \\
\text { ultrasonic machining }\end{array}$ & Quartz glass [112-114] & Improvement in accuracy and efficiency [112-114] \\
& & \\
\hline
\end{tabular}

\subsubsection{Water-assisted micro-machining}

It is possible to ablate micrometre range high aspect ratio holes in silicon, LCD glass and alumina by water-assisted femtosecond and $\mathrm{CO}_{2}$ laser pulse ablation. By applying thin water layer on the processed surface, holes can be drilled more efficiently and with less taper, micro-cracks and HAZ than in air atmosphere. Furthermore, with water, the ablation rate is about two times faster than without it. Reason for such improvements is the removal of the ablation debris from the processing area during the drilling process. When there is no thin water spray to collect and transport the debris away from the processing area, the ablation debris is blocking the energy transition into the ablation process itself. Debris scatters and absorbs the incoming pulses and therefore drilling is not so efficient. When water is used, it removes debris continuously away from the holes and therefore drilling process is equally efficient with following pulses. Scattering caused by debris is also inflicting the shape of the hole [99-102]. The drawback is that the ablated surface is somewhat rough as a result of rapid solidification of the molten material [103].

It has been reported that water can substantially improve the surface quality (topography, bump, debris, etc.) in excimer laser ablation of $\mathrm{Si}$ and $\mathrm{Al}_{2} \mathrm{O}_{3}$. Moreover, it has been found that laser ablation is enhanced at low laser fluences by water for polymethyl methacrylate (PMMA) while no enhancement is achieved by water for polyethylene terephthalate (PET). This striking difference suggests that the ablation mechanisms for the two polymer materials are different to a large degree. If ablation of a polymer by a ultraviolet (UV) pulse occurs entirely by the photochemical effect, the influence of liquid will be relatively insignificant, 
compared with a photothermal process in which hydrodynamics of the ablation plume and melt pool is important. Ablation of PET by a UV laser is largely dominated by a photochemical process while that of PMMA is significantly affected by a photothermal effect. The surface formed by excimer laser ablation of PET is smoother than PMMA, which also corroborates the above notion regarding the ablation mechanism of the two polymers [104]. Fig. 19 shows the schematic diagram of the laser ablation and experimental set-up of a workpiece under water.

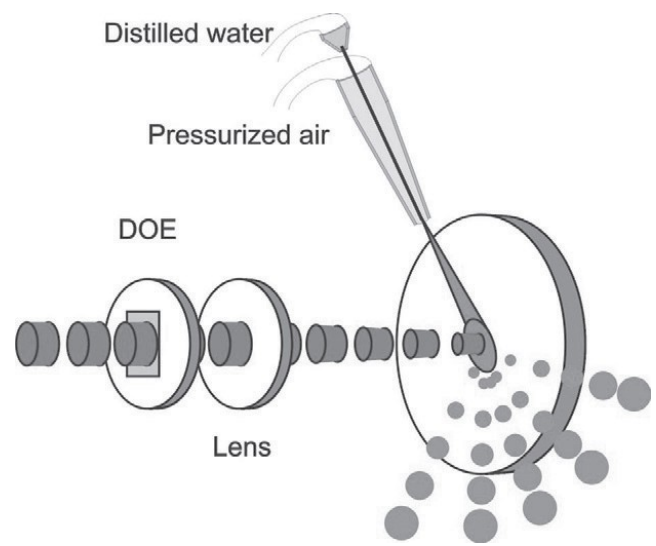

(a)

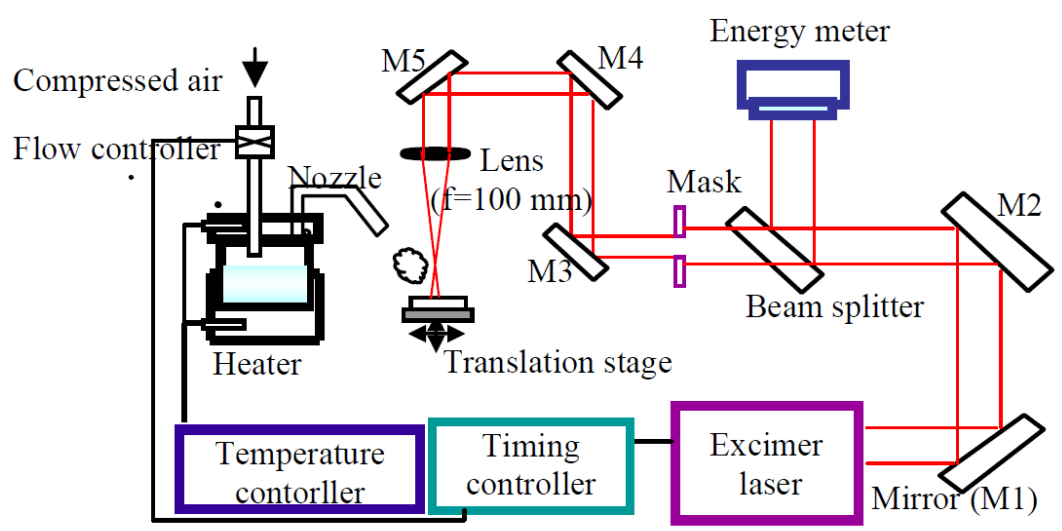

(b)

Fig. 19. Schematics of the water-assisted laser ablation setup [99, 104] 


\subsubsection{Gas-assisted micro-machining}

Laser micro-drilling of cooling holes in certain parts of the aero-engine components involves percussion or trepan drilling at acute angles to the surface. These parts are made of Nimonic 263 superalloy and often covered with plasma sprayed ceramic thermal barrier coatings (TBC) to protect them from reaching excessive temperatures in hot engine environments. Delamination of the TBC is the main problem of laser micro-drilling acute angled holes in the coated components. In order to address this problem, a technique is proposed based on the control of the melt flow trajectories and impact angle on the hole walls applying a secondary gas jet. A schematic of this process is depicted in Fig. 20. An off-axis gas jet impinging near the leading edge of the inclined hole during laser drilling process is introduced to control the trajectories and impact speed of the melt on the TBC walls. The off-axis jet is impinged at $90^{\circ}$ to the beam axis $\left(\alpha=90^{\circ}\right)$. The co-axial and off-axis nozzle exit to workpiece off-set distances are 8 and $4 \mathrm{~mm}$, respectively. Oxygen for the co-axial and nitrogen for the off-axis jets are used via $1.5 \mathrm{~mm}$ exit diameter converging nozzles. It has been demonstrated that a less erosive melt ejection occurs at the hole entrance and consequently melt ejection-induced TBC delamination was reduced or in some cases was completely prevented when microdrilling of $0.6 \mathrm{~mm}$ holes in TBC Nimonic 263 substrate material by using the technique. However, some cracks were observed at the $\mathrm{BC} /$ substrate interfaces owing to the changes in the melt and vapour flow introduced by secondary jet in the process. Nonetheless, these cracks were diminutive in both lengths and width and represented a lesser risk of further propagation [105]. 


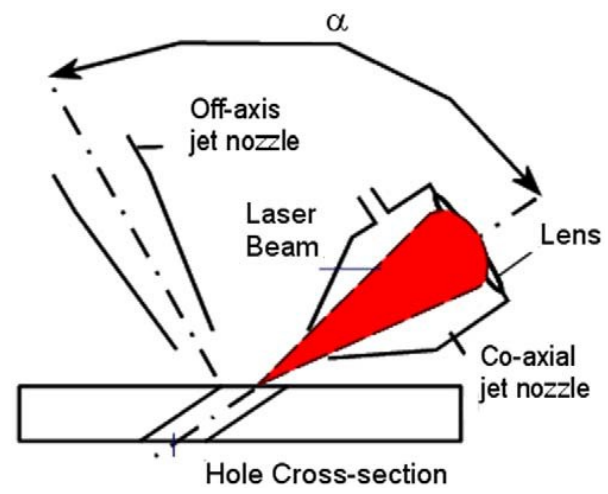

Fig. 20. Concept of twin gas jet-assisted laser micro-drilling [105]

\subsubsection{Chemical-assisted micro-machining}

In laser micro-drilling, instead of water, methanol can be used as a solvent to produce microholes with a relatively cleaner and smoother surface. The improvement of drilling quality can be attributed to the relatively lower boiling temperature and better wettability of the solvent, which enhance the effects of cooling (thermal damage free) and ablated particle cleaning during laser micro-drilling. A thin-layer liquid film can easily modify the optical properties of a surface. It can be explained that the reflective index of liquids (i.e., water and methanol) is greater than that of air; the overall surface absorptivity increases as the liquid film is applied on the surface. It is believed that plasma confinement is generated in a liquid environment at a higher radiant exposure regime (i.e., $1>\mathrm{GW} / \mathrm{cm}^{2}$ ), consequently inducing higher temperature, higher pressure, and higher density plasma (i.e., laser-induced plasma) at the Si surface when the laser pulse irradiated the surface of the solid target through the liquid, leading to more explosive removal of material. A methanol layer of $500 \mu \mathrm{m}$ is suggested to be used for the enhancement of laser ablation rate and quality in chemical-assisted laser micro-drilling of single crystalline silicon carbide [106]. Salt solution can be also used so as to improve the machining quality and material removal rate in laser micro-machining. HAZ 
size and recast are significantly reduced for both laser milling and drilling of 316 stainless steel material. Fig. 21 compares the HAZ of the holes machined in the salt solution and in air, exhibiting much reduced heat affected area in the case of salt solution. More importantly, up to $300 \%$ material removal rate increase is obtained compared that in air [107].

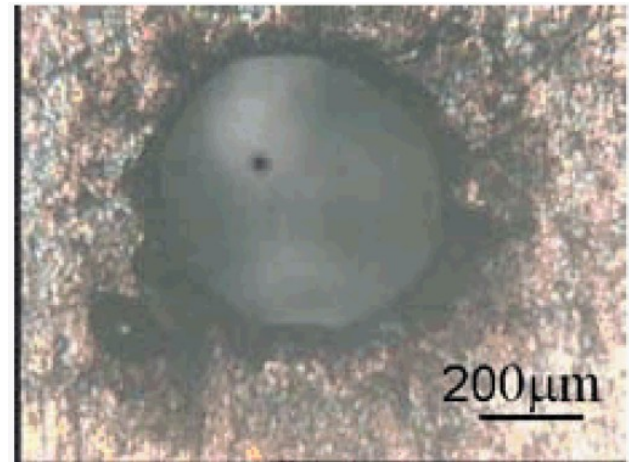

(a)

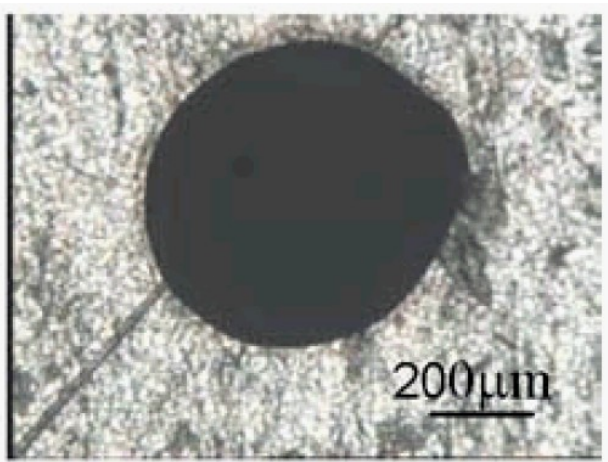

(b)

Fig. 21. Comparison of holes drilled in a) air, and b) in salt solution (workpiece material: 316

$$
\text { stainless steel) [107] }
$$

A low concentration of hydrofluoric (HF) acid is added to the abrasive slurry in USM (ultrasonic machining) in order to overcome the disadvantages of the conventional USM such as a low material removal rate and surface quality. In the process of the USM, materials are removed by micro-chipping or erosion with the abrasive particles. The tip of the tungsten carbide (WC) tool vibrates at low amplitude $(2-50 \mu \mathrm{m})$ and high frequency $(20 \mathrm{kHz})$, which transmits a high velocity to the fine abrasive grains between the tool and the surface of the workpiece. The chemical composition of the workpiece, the size of the abrasive particles and the static load affect the characteristics of ultrasonic machining. When glasses are dipped in 
the HF solution, the reaction between $\mathrm{Si}$ and the $\mathrm{F}^{-}$ions and the reaction between oxygen and the $\mathrm{H}^{+}$ions occur simultaneously, and the total chemical reaction can be described as Eq. (1).

$$
\begin{array}{cccc} 
& \equiv S i-O-S i \equiv S i+O-S i \equiv \\
F^{-} H^{+} & & F^{-} H^{+} & \\
& \rightarrow & F^{-} H^{+}
\end{array}
$$

When the HF solution reacts with the glass, the bonding forces between the Si molecules on the surface area become weakened. This phenomenon improves the efficiency of ultrasonic machining. Fig. 22 shows the difference in the machining mechanisms between the USM and the chemical-assisted ultrasonic machining (CUSM).

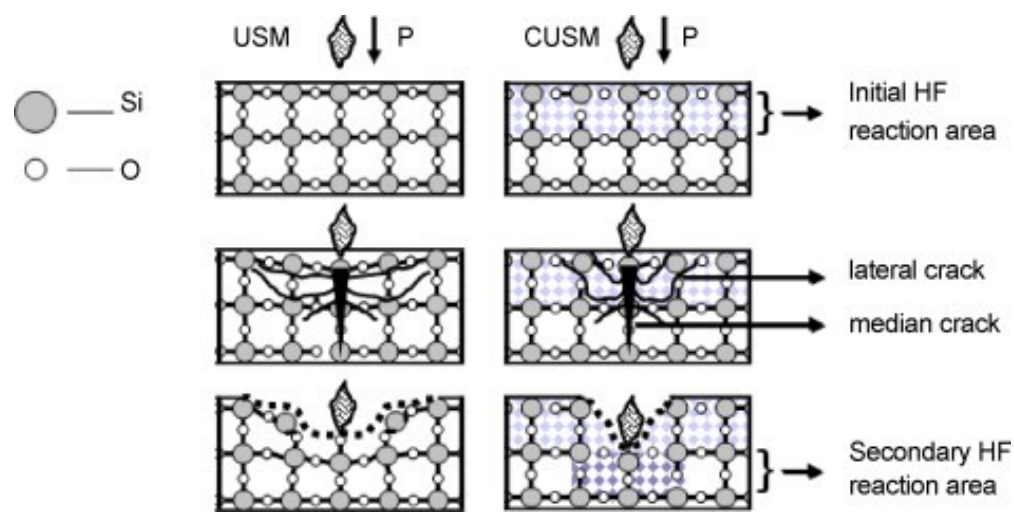

Fig. 22. Mechanisms of USM and CUSM [108] 
It is verified that the surface finish and the material removal rate are improved up to $40 \%$ at micro-drilling and $200 \%$ at macro-drilling by using CUSM. Also, the machining load is drastically reduced and can be maintained stably. The drawback of this process is that it enlarges the size of machining hole to a certain extent; it is recommended to use a relatively low concentration, under 5\%, HF solution [108].

Electrochemical passivation is applied in electrochemical-assisted micro-machining so as to alter mechanical properties of the workpiece. Electrochemical passivation causes generating a thin oxide layer on the substrate surface, which possesses lowerpoorer mechanical strength than the core material; hence, can be removed easily. The schematic of the electrochemically assisted micro-turning process is presented in Fig. 23. It should be noted that in this process the depth of cut ought to be in consistent with the thickness of created oxide (passive) layer. In 2014, Skoczypiec et al. [109] presented the conception of electrochemical assisted-microturning of 304 steel and concluded that the cutting depth should be in the range of $100 \mathrm{~nm}$.

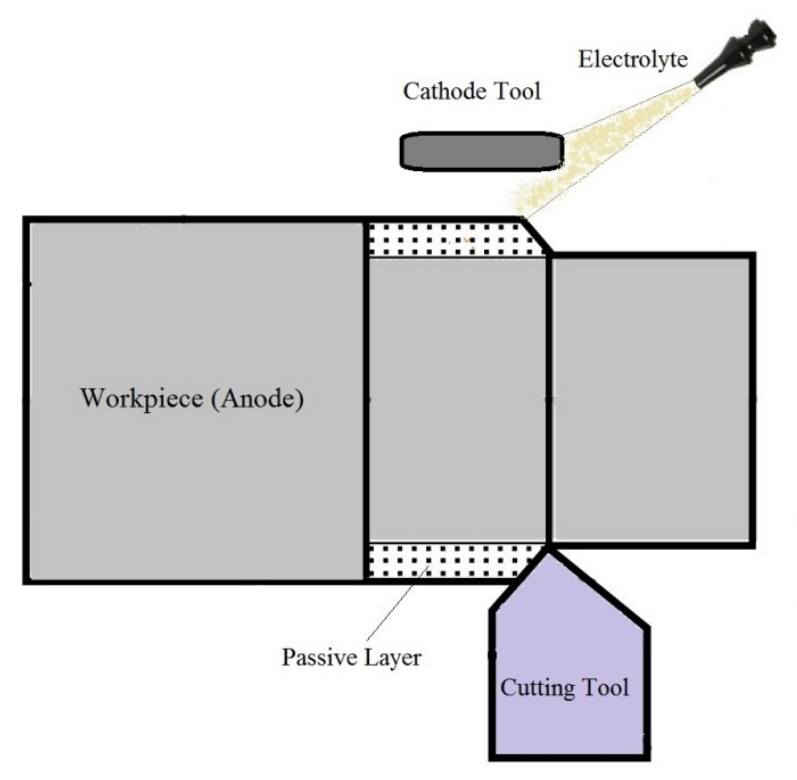

Fig. 23. Schematic of the electrochemical-assisted micro-turning (Redrawn from reference [109]) 
In order to minimize the problems associated with the micro-fabrication of hard-brittle materials by micro-ultrasonic machining such as occurrence of chipping and reduced machining accuracy, electrorheological (ER) fluid-assisted ultrasonic machining is proposed. ER fluid is a functional fluid in which viscosity increases with electric field intensity. The ER fluid was also called Winslow fluid which was discovered by Winslow [110]. It consisted of dielectric particles in the insulating fluid. These dielectric particles are polarized easily under high electric field strength and then the ER fluid will transform into a plastic flow. If the electric field were stronger, even the ER fluid will be solidified. Fig. 24 shows the mechanism for the electrorheological behaviour [111].
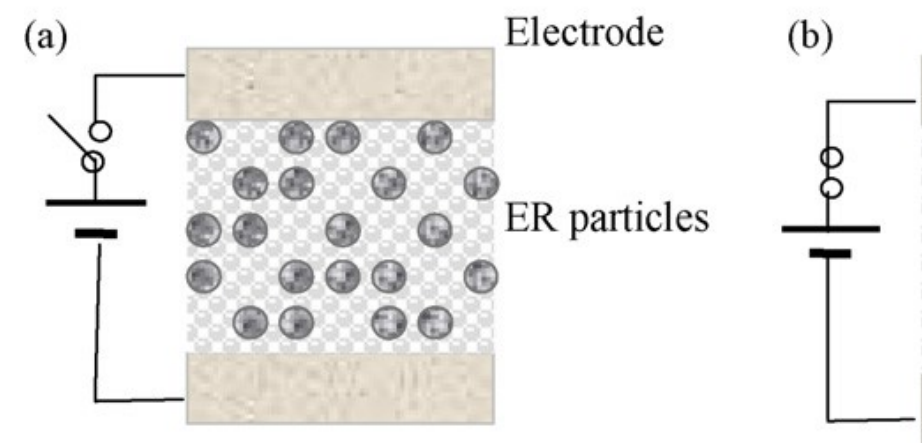

Dielectric polarization

Fig. 24. Schematic diagram of the mechanism for the electrorheological behavior: (a) without electric field and (b) with strong electric field [111]

In ER fluid-assisted ultrasonic machining, slurry, which is a mixture of ER fluid, abrasive grains, and dielectric oil, is applied in the cutting zone. An auxiliary circular electrode is utilized as the cathode on the workpiece surface and a vibrating micro-tool is used as the anode. Overall, as a non-uniform electric field acts on the cutting zone, electro neutral objects 
are affected by electric force. Consequently, abrasive grains are influenced by the electric forces and are driven toward the tool tip in the cutting zone (dielectrophoretic phenomena). Simultaneously, the viscosity of the ER fluid enhances under the electric field. Accordingly, abrasive grains are focused and fixed around the tool tip. In this manner, the workpiece can be machined by the concentrated abrasive grains with high accuracy and efficiency. Thus, in ER fluid-assisted ultrasonic machining, material is removed chiefly by the accumulation of tiny brittle fractures; hence, achieving high-accuracy and efficiency micro-fabrication of hard-brittle materials like quartz glass would become feasible [112-114].

\subsection{Magnetic field-assisted micro-machining}

A permanent magnet can be employed to establish a magnetic field in the machining zone. An experimental setup for magnetic field-assisted micro-EDM is shown in Fig. 25. By using such configuration in micro-EDM process, higher hole depth can be achieved owing to increase of the debris removal. The magnetic field inside the hole has vertical and horizontal components. The schematic representation of the magnetic field acting on the debris particle inside the hole being machined is given in Fig. 26, which indicates an increase in the vertical component of the magnetic force will augment the transport of ferromagnetic debris out of the hole. Conversely, the presence of the magnetic field causes some distortion in the tool electrode and increase of the tool wear and surface roughness [115]. 


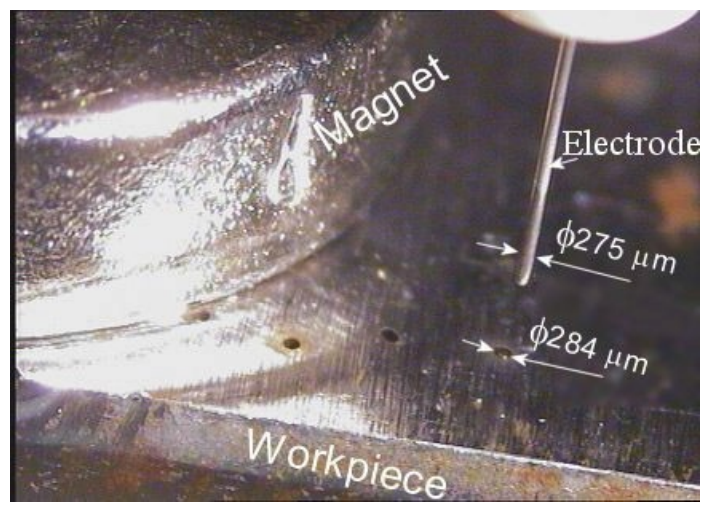

Fig. 25. Experimental setup for magnetic field-assisted micro-EDM (workpiece material: Hardened tool steel XW 42) [115]

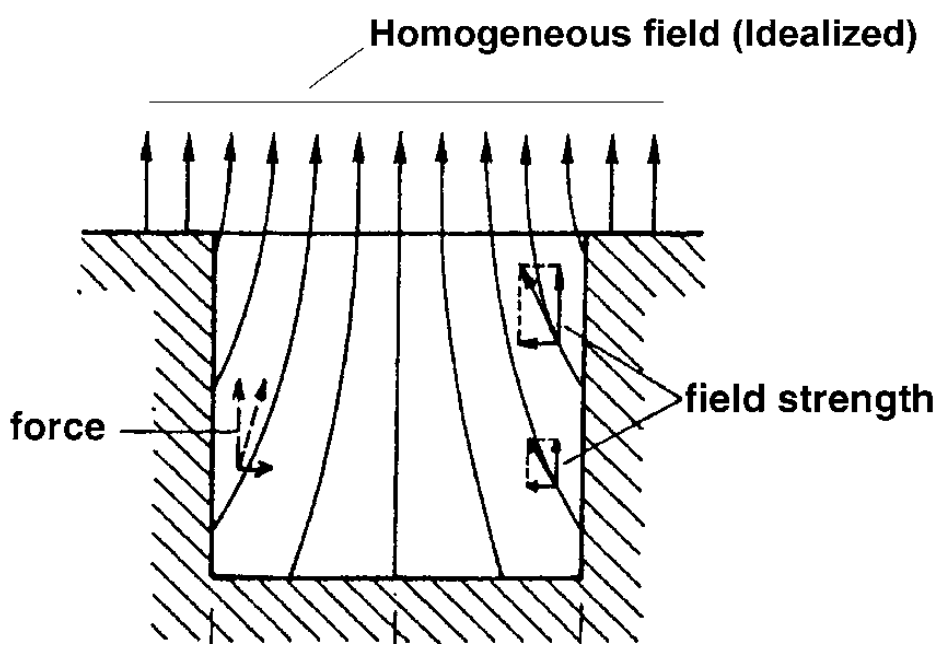

Fig. 26. Magnetic field inside a hole. The magnet is assumed to be on top of the hole and produce a homogeneous external field [115]

\subsection{External electric field-assisted micro-machining}

Introducing an electric field during micro-machining can assist to remove debris and prevent particles from redepositing onto the surface. A schematic of the experimental setup for external electric field-assisted femtosecond laser micro-machining and the device for 
providing an external electric field are presented in Fig. 27. Material removal with the femtosecond laser is a complex process. At femtosecond time scale, free electrons absorb laser energy and leave the sample surface in several picoseconds. The ultrashort laser pulses with mJ- pulse energy produce sufficiently high peak power that leads to ionization of the substrate material and therefore formation of the plasma. The presence of the plasma can lead to a large number of micro/nano-sized particles being deposited on the substrate surface. By introducing an electric field during the fs laser machining, redeposition of particles onto the surface can be inhibited. For the charged particles to be removed by the electric force, the particle weight needs to be smaller than the electric forces. Electric force is defined as follows:

$$
F=V * q / d
$$

where $F$ is the electric force experienced by the particle; $q$ is the charge of an electron, $-1.602 \times 10^{-19} \mathrm{C}, V$ is the applied voltage between two plates and $d$ is the distance between the two plates. Particle weight is:

$$
G=\left(\frac{r_{p}}{r_{a}}\right)^{3} m_{a} g
$$

where $r_{p}$ is the radius of the particle; $r_{a}$ is the radius of the $\mathrm{Si}$ atom, $0.117 \mathrm{~nm}, \mathrm{~m}_{\mathrm{a}}$ is the mass of the atom, and $g$ is the gravity acceleration, $9.8 \mathrm{~ms}^{-2}$.

When an external electric field is applied during the femtosecond laser micro-machining of silicon, a significantly improved machined surface quality with much reduced amount of surface contaminants is achieved, as depicted in Fig. 28 [116]. 


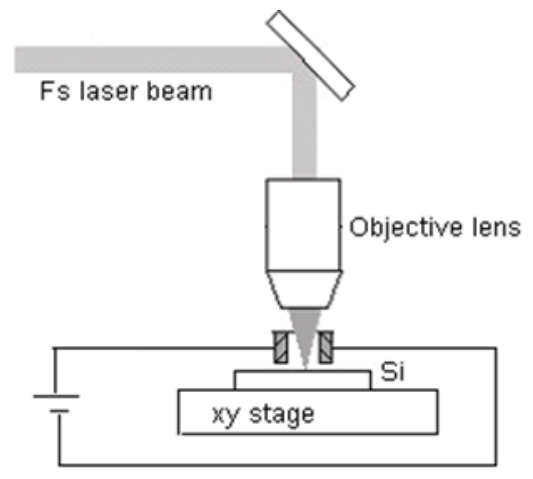

(a)

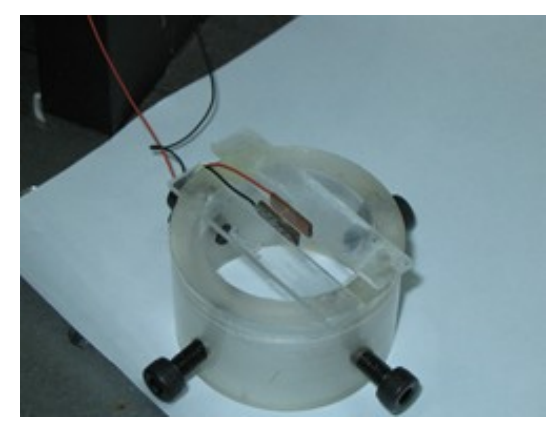

(b)

Fig. 27. (a) Schematic of the experimental setup for external electric field-assisted laser micro-machining (b) Device for providing an external electric field [116]

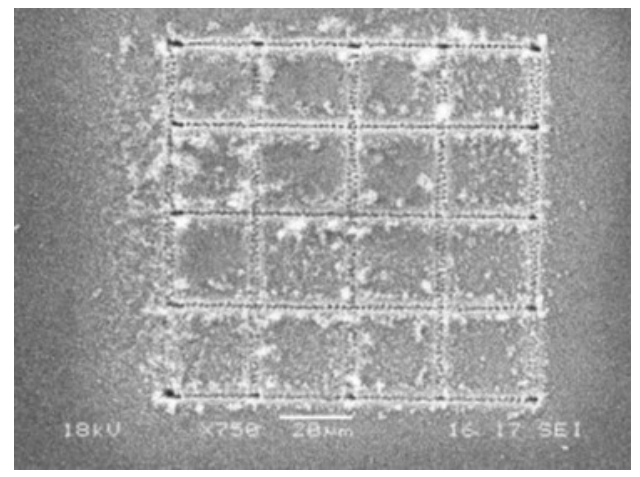

(a)

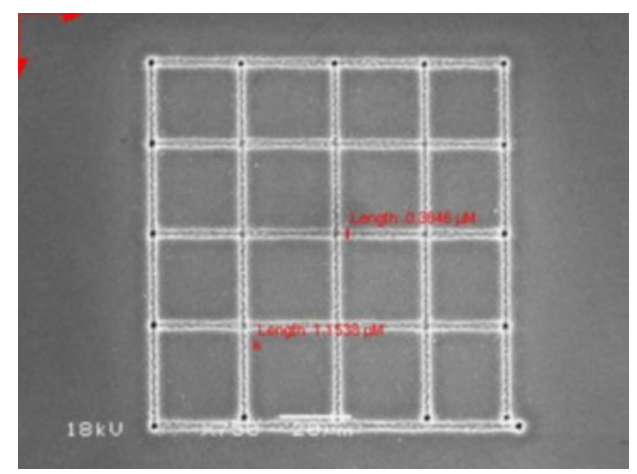

(b)

Fig. 28. fs laser micro-machining of silicon a) without the external electric field. b) with the external electric field [116]

\subsection{Carbon nanofibre-assisted micro-machining}

As schematically shown in Fig. 29, unlike the conventional EDM and powder assisted EDM, carbon nanofibers can arrange themselves in the form of micro-chains by interlocking which helps to form bridging networks between electrode and workpiece. Due to excellent electrical 
conductivity of carbon nanofibre, it can be applied in micro-EDM dielectric fluid in order to reduce the insulating strength of the dielectric fluid and increase the spark gap distance between the electrode and workpiece. As a result, the frequency of electro discharge and the material removal rate in the $\mathrm{EDM}$ of $\mathrm{RB}-\mathrm{SiC}$ is improved. In addition, multiple fine discharges are occurred under this situation, leading to a reduction in crater size on the workpiece surface, and in turn, a better surface finish might be obtained. It has been found that the addition of carbon nanofibre reduces the electrode wear and electrode tip concavity [117].
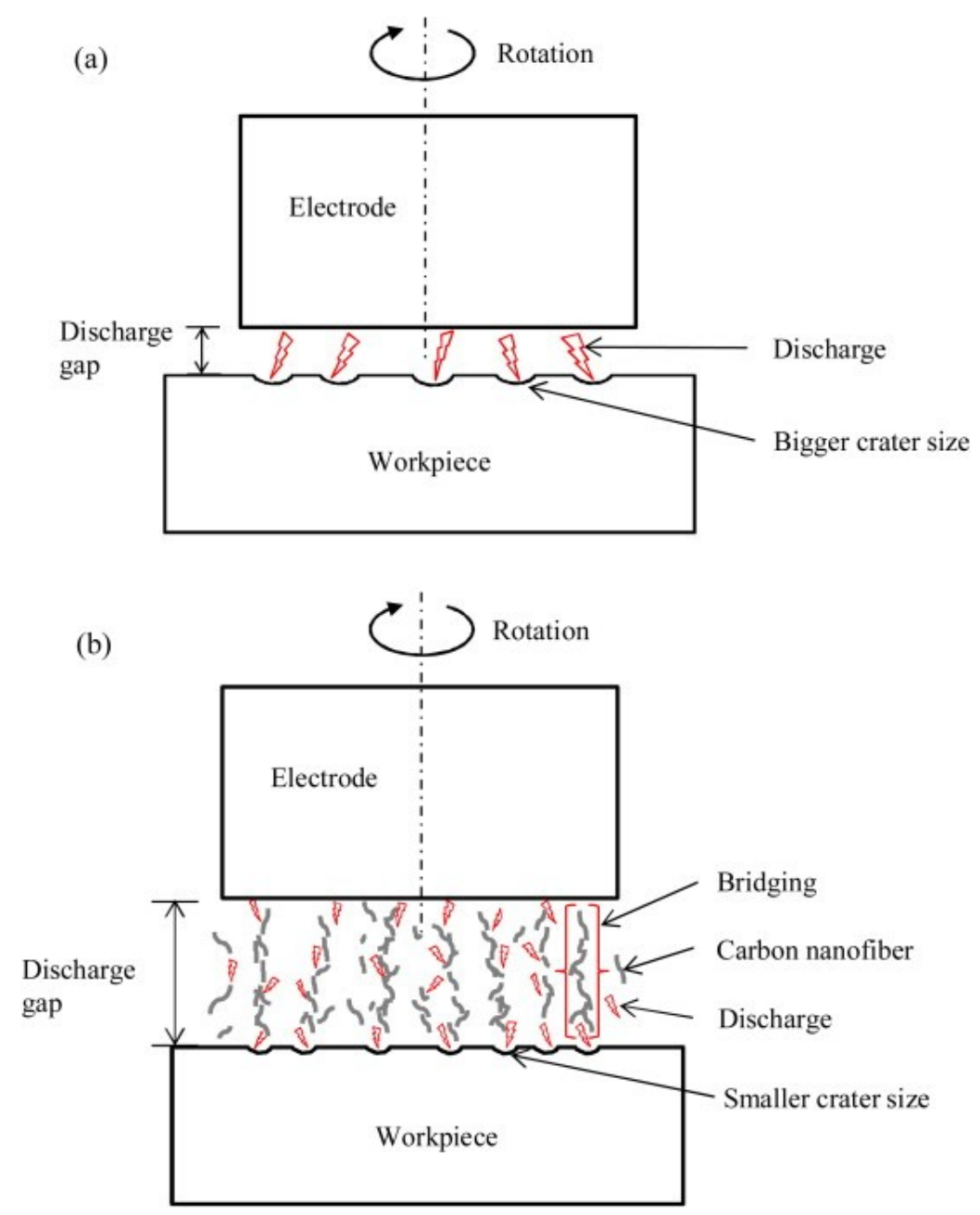
Fig. 29. Schematic model for (a) conventional EDM and (b) carbon nanofiber-assisted microEDM [117]

\subsection{Vibration and magnetic field-assisted micro-machining}

Simultaneous application of magnetic force and ultrasonic vibration in micro-machining process can improve the efficiency, surface roughness and stability of the process. In electrochemical micro-machining, it helps discharging dreg out of the electrode gap. Fig. 30 illustrates a schematic view of vibration and magnetic field-assisted electrochemical micromachining setup which is composed of a magnetic mechanism, DC (direct current) power supply, pulse-generators, pump, flow meter, and filter [118].

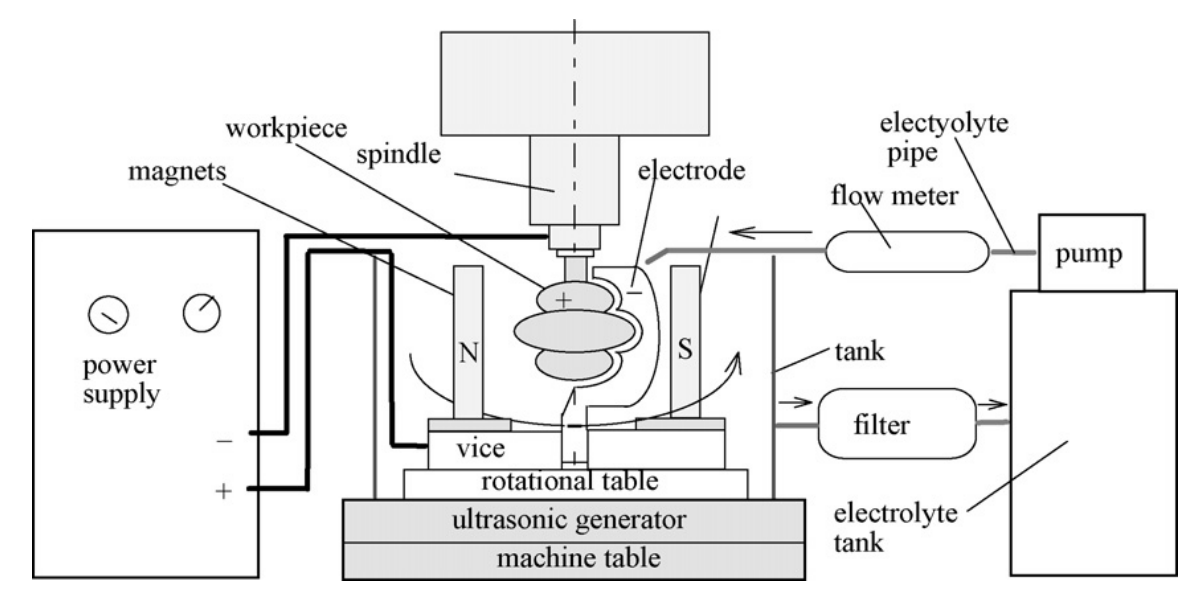

Fig. 30. Schematic view of vibration and magnetic field-assisted electrochemical micromachining setup [118]

Polishing process can be improved by using a magnetostrictive vibrating polisher shown in

Fig. 31. The form accuracy of binderless tungsten carbide workpiece is enhanced to less than 
$100 \mathrm{~nm} \mathrm{P-V}$ and the surface roughness is reduced to $3.3 \mathrm{~nm} \mathrm{Rz}(0.4 \mathrm{~nm} \mathrm{Ra})$ by using this polisher [119-121].

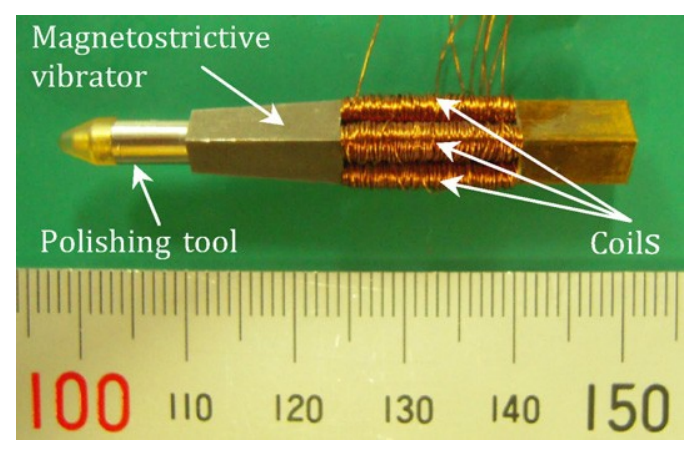

Fig. 31. 4-coil magnetostrictive vibrating polisher [120]

\section{Combined hybrid micro-machining processes}

In combined hybrid micro-machining, all the constituent micro-machining processes simultaneously contribute to the material removal and affect the machining zone. Combined hybrid micro-machining processes have giant potential to produce more complex parts with enhanced material removal rate, surface integrity and dimensional accuracy in a relatively short production time. Primary research in combined hybrid micro-machining field is on the application of electrical and electrochemical phenomena. Although combined hybrid micromachining processes such as ECDM have been mostly used to fabricate 3D micro-shapes on nonconductive materials like glass and quartz, there is still a lack of such processes for manufacturing complicated 3D micro-structures. Table 4 summarizes the reported work in the area of combined hybrid micro-machining. 
Table 4. Combined hybrid micro-machining processes

\begin{tabular}{|c|c|c|}
\hline $\begin{array}{l}\text { Combined hybrid micro- } \\
\text { machining }\end{array}$ & Work material & Primary characteristic \\
\hline ECDM & $\begin{array}{c}\text { Glass [126-128, 131-132,137, } \\
\text { 146-147, 150], Pyrex glass [130, } \\
\text { 135, 139], Soda lime glass [133, } \\
\text { 143, 152], Steel [142], Quartz } \\
\text { [140-141, 143], 100Cr6 steel } \\
\text { [149], Silicon nitride [129], } \\
\text { Borosilicate glass [148], Copper } \\
\text { [143], Tantalum [143], SS304 } \\
\text { [151], Al } \mathrm{O}_{3} \text { [145], E-glass-fibre- } \\
\text { epoxy composite [134], Silica } \\
\text { glass [138] }\end{array}$ & $\begin{array}{l}\text { Suitable for micro-machining of non-conductive } \\
\text { materials }[126-141,144-148,150,152] \\
\text { Achieved surface roughness }(\mathrm{Rq}) \text { for Pyrex glass is } \\
\text { nearly } 0.08 \mu \mathrm{m}[130]\end{array}$ \\
\hline ECDM milling & Glass [136], Pyrex glass [134] & $\begin{array}{l}\text { Suitable for 3D micro-structuring of non-conductive } \\
\text { materials }[134,136] \\
\text { Achieved surface roughness (Ra) for Glass is } 0.099 \mu \mathrm{m} \\
\qquad[136]\end{array}$ \\
\hline $\begin{array}{c}\text { Simultaneous ED-EC } \\
\text { milling }\end{array}$ & $\begin{array}{c}\text { SUS304 [1, 153-156], T1 copper } \\
\text { [157], 1Cr18Ni9Ti stainless steel } \\
\text { [157] }\end{array}$ & $\begin{array}{l}\text { Achieved surface roughness }(\mathrm{Ra}) \text { for SS304 is } 22 \mathrm{~nm}[1, \\
\qquad 153-156]\end{array}$ \\
\hline ECM-Grinding & SS321 [158] & Achieved surface roughness (Ra) is $0.21 \mu \mathrm{m}[158]$ \\
\hline $\begin{array}{l}\text { EDM- Electrorheological } \\
\text { fluid-assisted polishing }\end{array}$ & $\begin{array}{l}\text { SUS304 [111], } \\
\text { Aluminium alloy [159] }\end{array}$ & $\begin{array}{l}\text { Achieved surface roughness (Ra) for SUS304 is 0.06- } \\
\qquad 0.08 \mu \mathrm{m}[111]\end{array}$ \\
\hline Laser drilling-Jet ECM & 321 stainless [162] & More than $90 \%$ reduction in recast $[162]$ \\
\hline
\end{tabular}




\subsection{Micro-electrochemical discharge machining}

Micro-ECDM process involves a complex combination of the electrochemical (EC) reaction and electrodischarge (ED) action. The electrochemical action helps the generation of the positively charged ionic gas bubbles, e.g. hydrogen $\left(\mathrm{H}_{2}\right)$. The electrical discharge action takes place between the tool and the workpiece due to the breakdown of the insulating layer of the gas bubbles as the DC power voltage is applied between the tool (or cathode) and the anode, resulting in material removal due to melting, vaporisation of the workpiece material and mechanical erosion. Gas bubble formation and sparking phenomena as in the ECDM process are exhibited as shown in Fig. 32 [122].

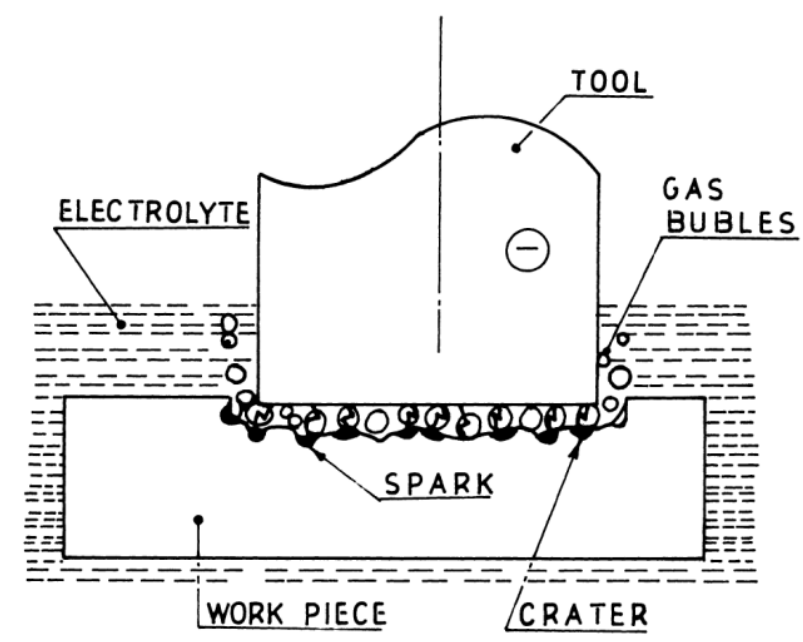

Fig. 32. Material removal mechanism of ECDM operation [122]

The process involves a DC voltage being applied between the electrodes immersed in an electrolytic solution as shown schematically in Fig. 33. The tool is generally used as a 
cathode to avoid anodic dissolution. The anode has a large surface area as compared to the tool and is kept at a distance from the cathode [123].

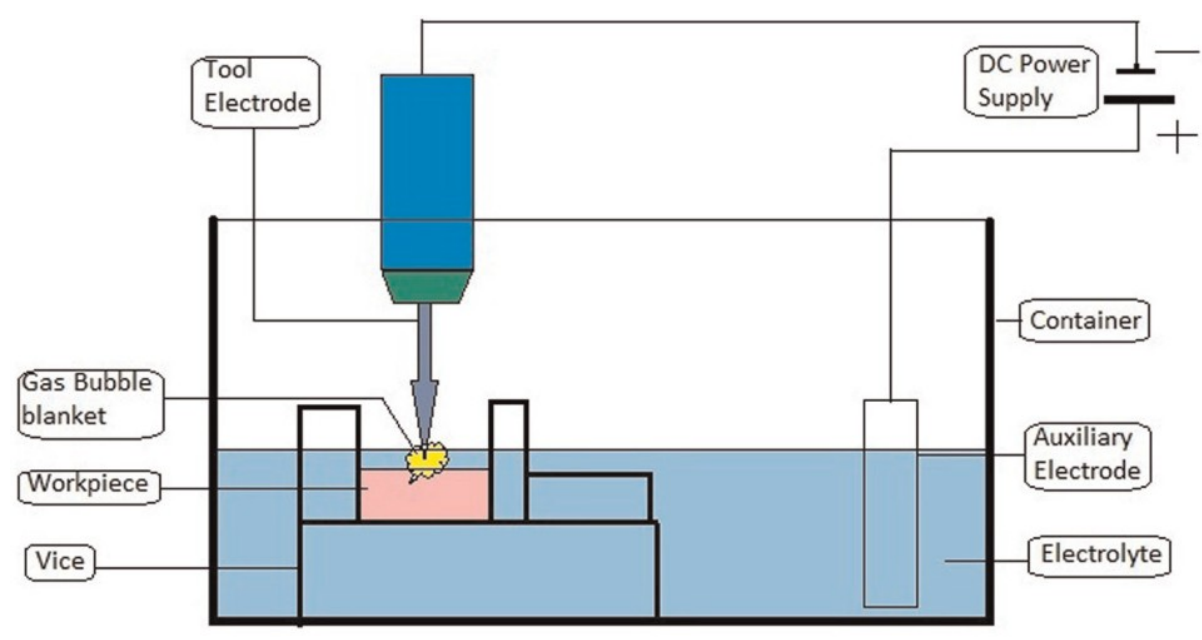

Fig. 33. Schematic of ECDM Process [124]

Several names had been used for this process such as electrochemical spark machining (ECSM), electrochemical arc machining (ECAM), spark-assisted chemical engraving (SACE) etc. [125].

A large number of studies have been reported on the investigation of different assets of micro-ECDM [126-152], such as wettability of the tool electrode [126], gas film thickness [127, 135, 139], different drilling regimes [128], characterization of various process parameters and state variables [129, 131, 144, 147-148, 150], application of rectangular voltage pulses in order to reduce HAZ [130], feasibility study of micro-machining of different shapes and materials [132-134, 136, 142-143, 146, 151-152], material removal mechanism [137], use of resistor-capacitor (RC) circuit [138], transition voltage [139], material and shape of the tool electrode [140-141, 145] and simulation of the heat transfer 
[149]. It is shown that applied voltage has more significant effects on MRR, radial overcut (ROC), HAZ thickness than other machining parameters such as electrolyte concentration, tool immersion depth and inter-electrode gap in micro-ECDM $[129,150]$.

Fig. 34 depicts various 3D structures machined by using ECDM micro-milling process on Pyrex glass [134]. It shows that the ECDM micro-milling process has great potential for the 3D micro-structuring of nonconductive and hard-brittle materials.
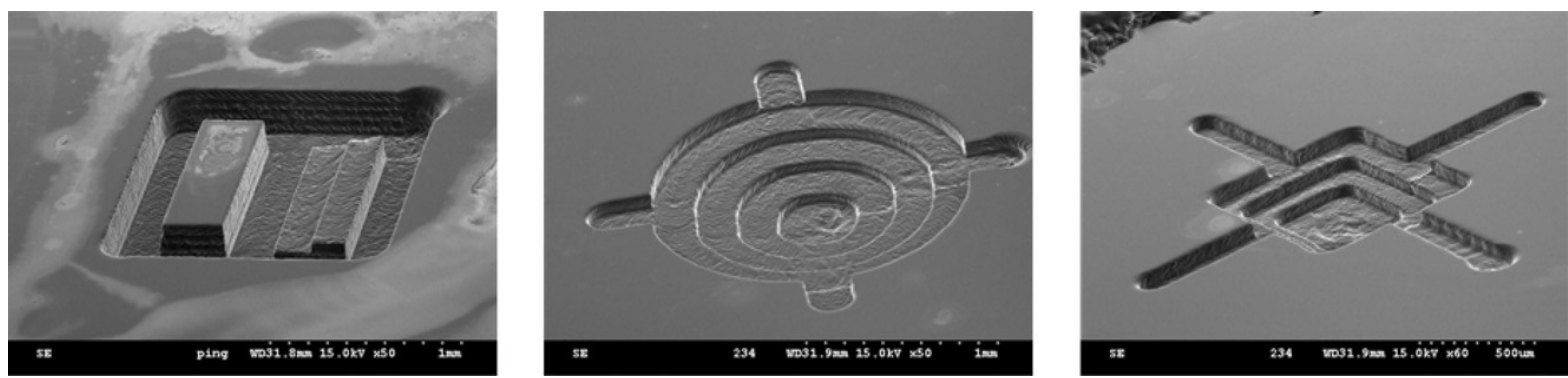

Fig. 34. Various examples of 3D micro-structures of Pyrex glass [134]

\subsection{Simultaneous micro-ED/EC milling}

In simultaneous micro-EDM and micro-ECM milling (SEDCM milling), material removal phenomenon in low-resistivity deionized water is exploited in such a way that the electrochemical reaction occurs concurrently with electrical discharge in a unique process. Fig. 35 illustrates the fundamental mechanism of SEDCM milling. In this method, material is removed layer-by-layer to maintain the original shape of electrode [1, 153-156]. 


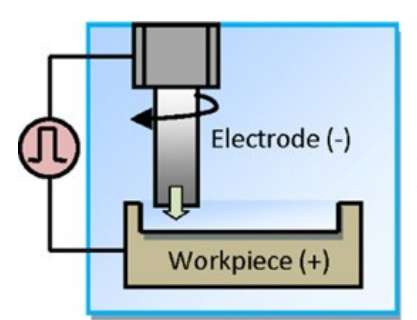

(a) Vertical feeding

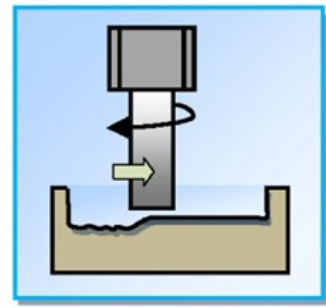

(d) Horizontal feeding

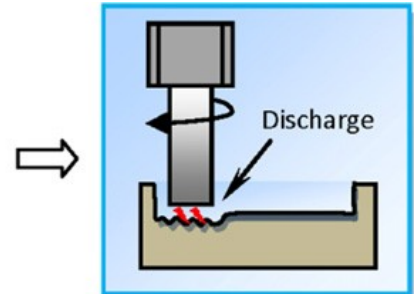

(b) Discharge
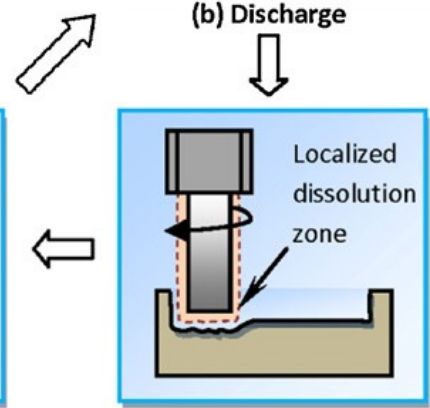

(c) Dissolution

Fig. 35. Principle of SEDCM milling [154]

SEDCM milling is capable of producing micro-shapes with enhanced surface integrity and dimensional accuracy. Micro-shapes with $22 \mathrm{~nm}$ Ra can be obtained on SUS304. Fig. 36 shows two examples of three-dimensional micro-cavities with a central island machined by micro-EDM milling and SEDCM milling, demonstrating the feasibility and capability of SEDCM milling process [154]. However, this process causes excessive electrolytic-erosion and workpiece surface damage as slight electrical conductivity always exists in deionized water. It is recommended to apply nanosecond voltage pulse and epoxy resin side-insulated tool electrode to suppress excessive electrolytic-erosion [157].
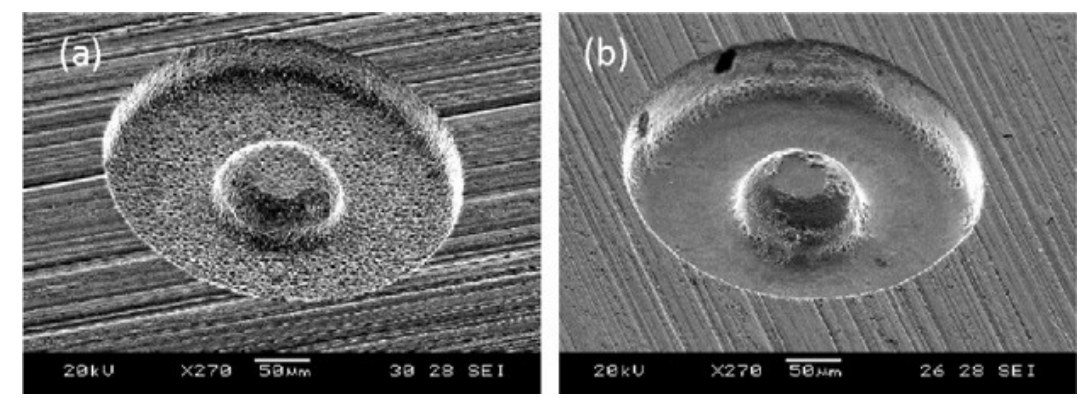
Fig. 36. 3D micro-cavities fabricated by different machining conditions: (a) micro- EDM milling and (b) SEDCM milling (workpiece material: SUS304) [154]

\subsection{Micro-ECM and micro-mechanical grinding}

Hybrid process of electrochemical material removal and mechanical grinding for machining of precision small holes was established in 2011. As demonstrated in Fig. 37, a spherical metal rod with coated diamond abrasives as cathode tool rotates at high speed and removes material electrochemically and mechanically for a pre-machined pilot hole. The pilot hole with diameter of $D_{0}$, which is smaller than the final hole diameter $D_{1}$. It is essential that the tool core is electrically conductive and the abrasive is electrically non-conductive. During the machining process, the tool is charged negatively and the workpiece performs as the anode. The abrasive particles (diamond particles) in the tool protrude beyond the conductive bond surface (nickel layer). This establishes a small gap between the tool nickel layer and hole side wall. In the proposed process, workpiece material removal occurs in two phases, as indicated in Fig 37. Electrolytic action begins when the gap is filled with an electrolyte and the tool is electrically charged. Phase 1 is entirely electrochemical action. In this phase, passivation film occurs on the hole surface because passive electrolyte $\mathrm{NaNO}_{3}$ is used. Phase 2 is a combination of electrochemical action and mechanical grinding. As the abrasive tool feeding down, the gap decreases until the abrasives on the tool base comes into contact with the workpiece. The abrasive grains act to remove the soft, non-reactive passivation layer, thus exposing fresh metal for electrolytic reaction. Simultaneously, the electrolyte trapped between the protruding abrasive grains and the workpiece forms tiny electrolytic cells, thus electrochemical dissolution of workpiece materials occurs. So in phase 2 material is removed from the workpiece surface by both electrochemical dissolution and mechanical abrasive 
grinding. Phase 2 ends at the point where the maximum tool diameter is. For obtaining sharp edges and high dimensional accuracy of hole, the tool should be insulated except the first half of the sphere. So, there is no removal action taking place in phase 3. If the tool is not insulated, the electrochemical dissolution will continue for the machined hole surface (phase 3) because of the electrical field between the machined hole surface and the tool, resulting in a taper hole. The finest surface finish of $0.21 \mu \mathrm{m}$ can be obtained in stainless steel 321 work material [158].

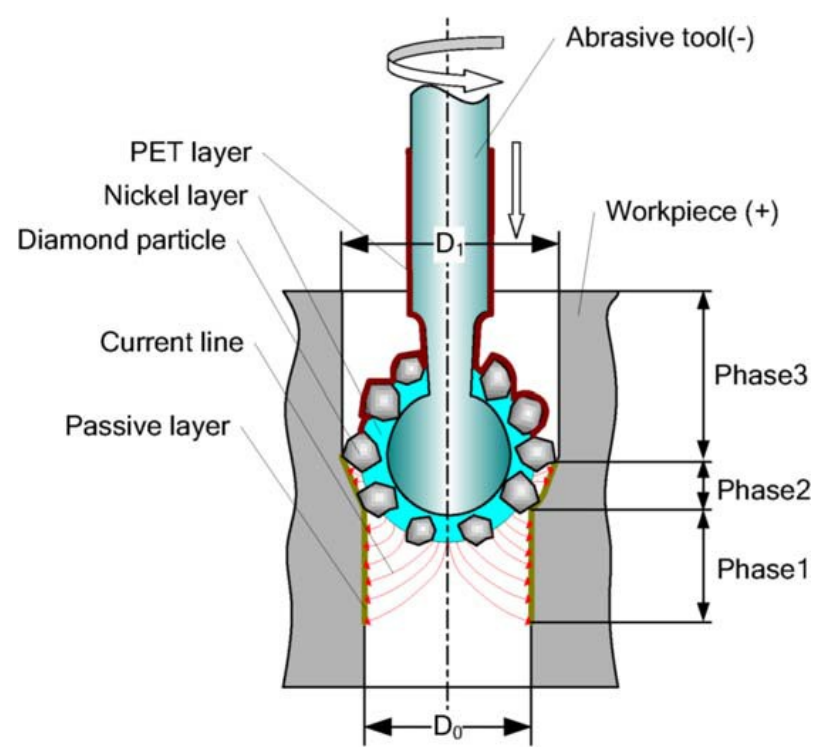

Fig. 37. Schematic view of the proposed hybrid process of electrochemical removal and grinding [158]

\subsection{Micro-EDM and electrorheological fluid-assisted polishing (ERP)}

Since there is very strong electric field between workpiece and electrode before discharge occurrence in EDM, it is possible to induce the electric field to assist polishing in microEDM. The principle of the combined machining process of EDM and ERP is schematically 
shown in Fig. 38. The copper micro-tool electrode is positive pole, and workpiece of conductive material is used as negative pole, which retains narrow gap between electrodes. When the external electric field is applied, the material is melted and vaporized instantaneously as result of intense heat generated in the gap. Meanwhile, the dispersed particles aggregate into cluster and fibrous structure aligned in the electric line due to the dielectrically polarized in ER fluid with fine abrasive particles, as shown in Fig 38. When the chain of particles contacts with workpiece surface with the rotation of the micro-tool, the abrasive particles indent into workpiece surface under normal pressure. In this technique, alumina and $\mathrm{SiC}$ can be used as abrasives [111, 159].
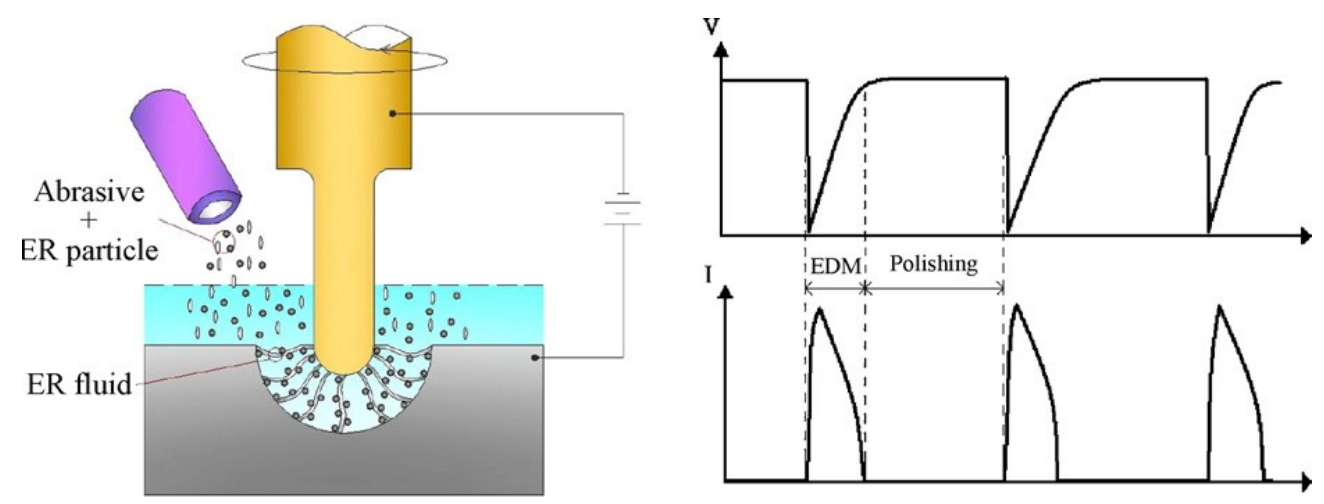

Fig. 38. Schematic diagram of the proposed method using ER fluid and abrasive gifts [111]

\subsection{Laser micro-drilling and jet ECM}

Laser drilling assisted with jet electrochemical machining (JECM-LD) combines two different sources of energy simultaneously: energy of photons (laser drilling) and energy of ions (ECM). The electrolyte jet and the focused laser beam coaxially aligned with it creating a contactless tool-electrode and strike against the same spot on the workpiece surface. During JECM-LD, the workpiece material is removed with laser action in pulse width, and then 
recast and spatter are reduced with electrochemical reaction in the inter-pulse of laser. Fig. 39 illustrates the principles of JECM-LD. It is found that the spatter is reduced more than $95 \%$, and recast is reduced more than $90 \%$ during the JECM-LD of 321 stainless steel compared with laser drilling in ambient atmosphere conditions [160-162].

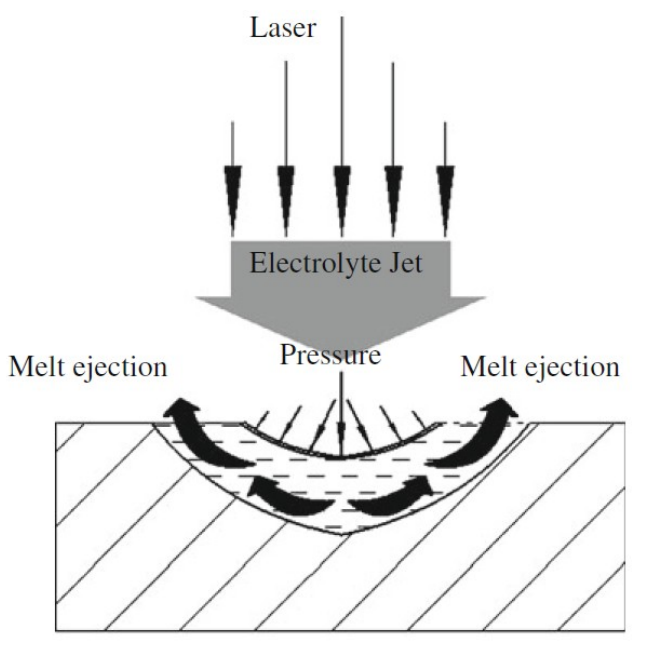

(a) In pulse width

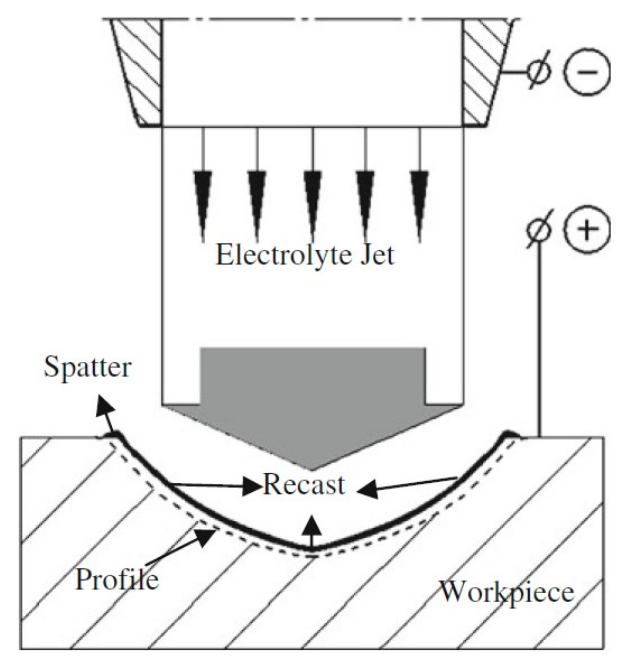

(b) In the inter-pulse

Fig. 39. Principle scheme of JECM-LD [162] 


\section{Case studies on integration of hybrid micro-machining with other micro-machining and assisted techniques}

Hybrid micro-machining processes can be integrated with other micro-machining and assisted methods so as to gain advantages of other techniques. The development and application of these types of processes should be as such that they enhance the benefits and minimize the potential drawbacks found in the individual hybrid techniques. This category of processes gives new possibilities to machine materials or shapes with higher accuracy and improved surface quality which could not be manufactured or achieved by single hybrid micro-machining techniques. Despite its numerous advantages, a little work has been performed in this field. Hence, development of this sort of micro-machining processes is a promising area of research. The following paragraphs give details of the studies done on the combination of hybrid micro-machining processes with other micro-machining and assisted methods.

\subsection{Combined and assisted hybrid processes}

Vibration and magnetic field can be applied in combined hybrid processes to improve the performance of these processes. An ultrasonic-vibrated electrolyte in micro-ECDM enhances the machining depth by assuring an adequate flow of electrolyte for spark generation and chip removal in the gap between the tool and the workpiece [163]. Moreover, it is shown that the magneto-hydrodynamic convection induced by the magnetic field can effectively enhance electrolyte circulation, which contributes to higher machining performance. The improvement in the geometry accuracy achieved in magnetic field-assisted micro-ECDM of 
glass is $23.8 \%$ while that in machining time reaches $57.4 \%$. A schematic diagram of the magnetic field-assisted ECDM apparatus is shown in Fig. 40 [164]. In vibration-assisted micro-ECDM drilling of borosilicate glass, the machining depth increases from $320 \mu \mathrm{m}$ to $550 \mu \mathrm{m}$ compared to conventional micro-ECDM drilling results [163].

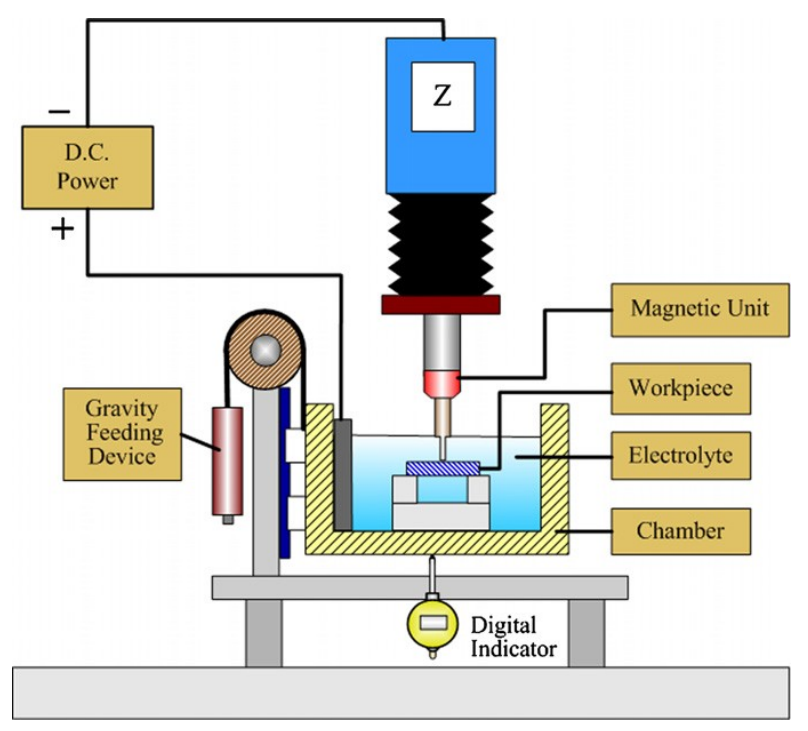

Fig. 40. Schematic diagram of the magnetic field-assisted ECDM apparatus [164]

\subsection{Combined and sequential hybrid processes}

In this method, micro-structures are machined by ECDM milling and then ground by PCD tools to improve the surface quality. The concept of this hybrid process is shown in Fig. 41. 


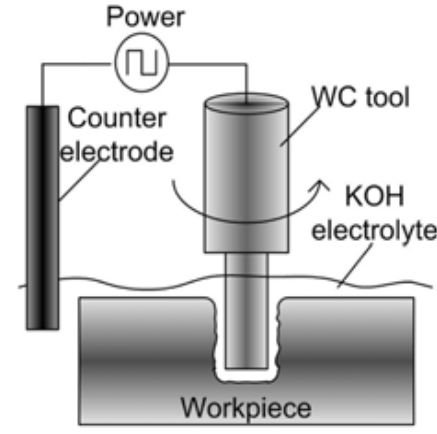

Pre-machining by ECDM

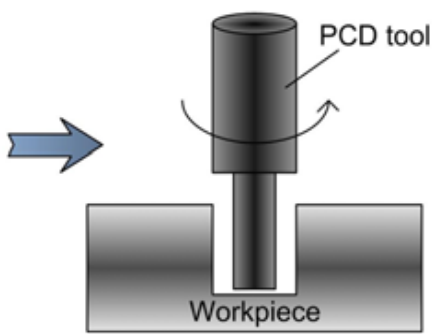

Post-machining by PCD grinding

Fig. 41. Concept of the hybrid machining process [165]

A surface roughness, Ra, of $0.05 \mu \mathrm{m}$, sharp rims and edges can be achieved in glass workpiece by using this process. Fig. 42 shows a micro-groove and column in a soda lime glass workpiece machined by ECDM and after the postmachining step [165].
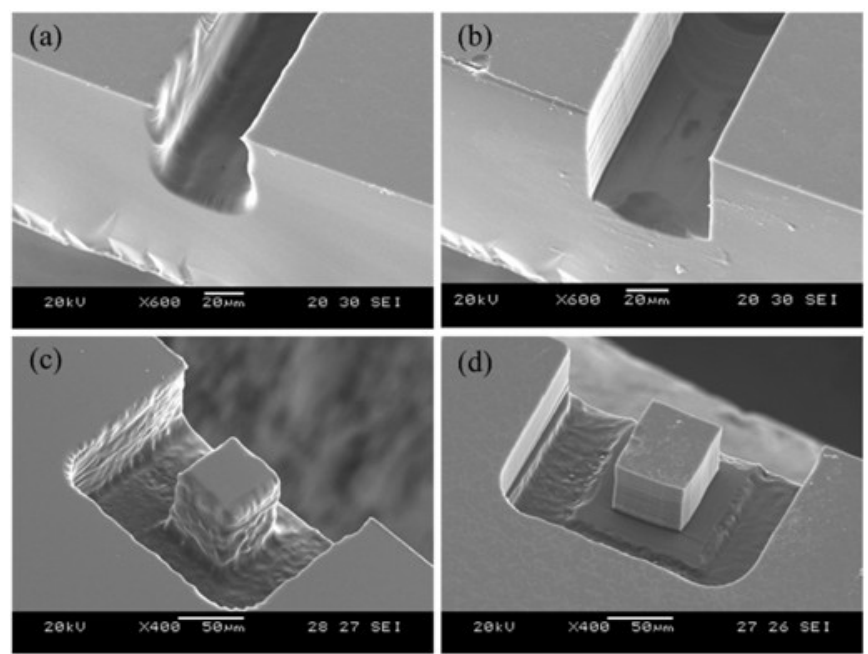

Fig. 42. Micro-structures machined by $(\mathrm{a}, \mathrm{c})$ ECDM and $(\mathrm{b}, \mathrm{d})$ then ground by a PCD tool 
WEDG and EDM combined with HFDG (high frequency dither grinding) can be integrated to produce micro-holes with high surface quality. Fig. 43 shows the experimental set-up. As can be seen, the set-up consists of an EDM machine, a WEDG mechanism, a four-axis control system, and a HFDG mechanism. The WEDG mechanism is fixed on the EDM worktable, while the four-axis control system is fixed onto the EDM machine head. The HFDG mechanism, displayed in Fig. 44, is made up of a function generator, a power amplifier, reeds and piezoelectric ceramics. During operation, the workpiece is fixed at the centre of the dither mechanism.

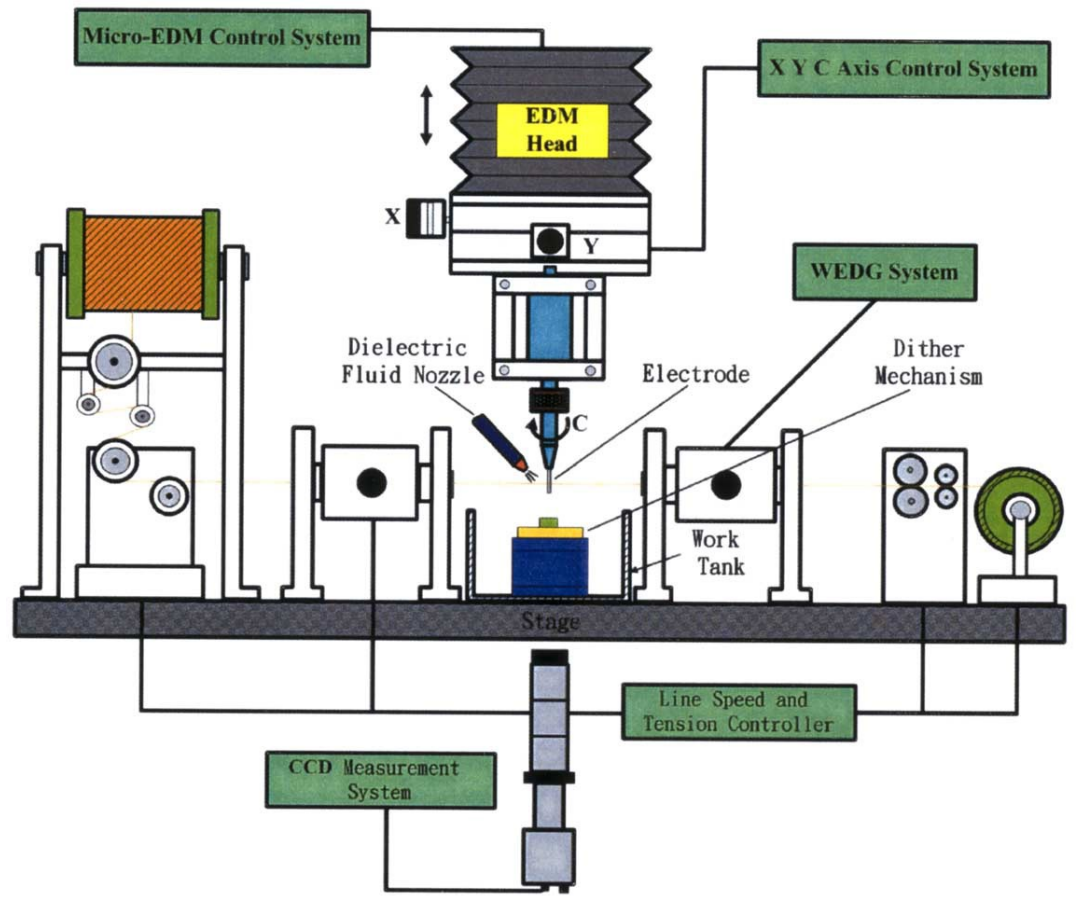

Fig. 43. Configuration of micro-EDM system with built-in WEDG [166] 


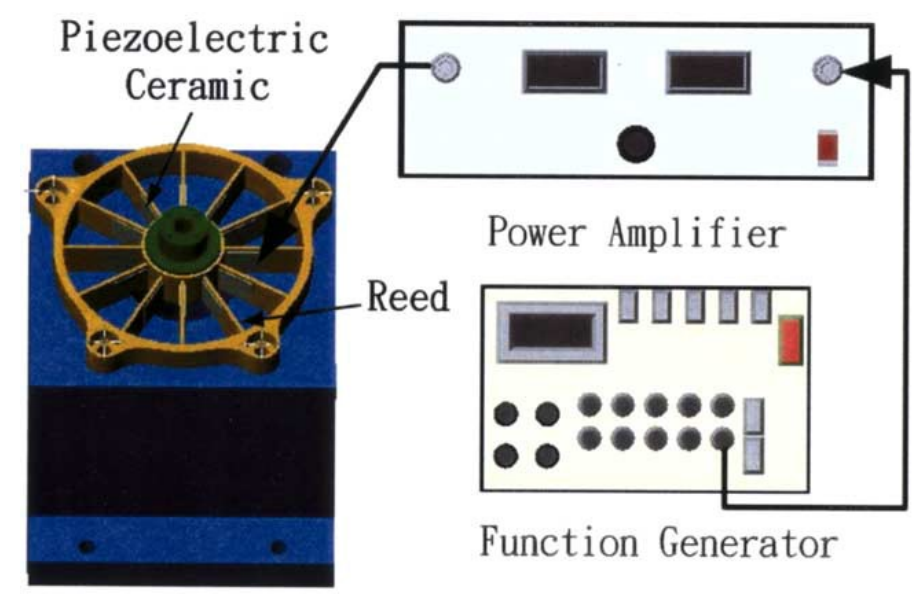

Fig. 44. Schematic of HFDG mechanism [166]

First, a circular rod of tungsten carbide is machined using WEDG. The machined rod is then used to drill micro-holes on the workpiece. Alumina $\left(\mathrm{Al}_{2} \mathrm{O}_{3}\right)$ particles are added to the slurry in the tank. The EDM machine is coupled with the HFDG mechanism to polish the microholes by upward and downward machining. The entire operation does not involve any dismounting of the machining electrode or tool, thus avoiding the eccentric problem of the rotating tool. HFDG method can reduce machined surface roughness (Rmax) on Hymu 80 workpiece from $2.12 \mu \mathrm{m}$ to $0.85 \mu \mathrm{m}$ with micro-cracks eliminated [166].

\subsection{Sequential and assisted hybrid processes}

Production of cooling holes less than $1 \mathrm{~mm}$ diameter in electrically non-conductive ceramic coated nickel alloy presents a number of problems as the preferred ceramic material is alumina. This is effectively an electrical insulator with a specific electrical resistance $\geq 100$ $\Omega \mathrm{cm}$ and therefore EDM is not viable. One solution is the use of USM to penetrate the ceramic coating followed by tool vibration-assisted micro-EDM drilling. Fig. 45 shows 
general views of the experimental set-up for this process. The use of appropriate tool material is critical in this hybrid process in order to obtain effective USM/EDM operation. Preferred USM tool materials are not ideal for EDM and vice versa. Mild steel is proved reasonably effective; however, tool wear is significant [167].

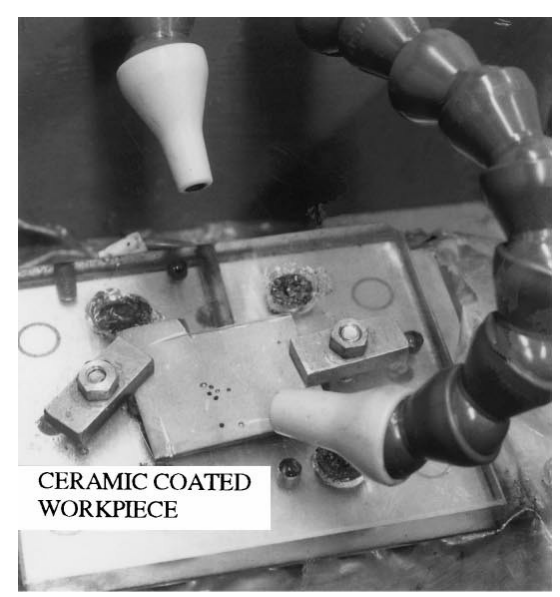

a)

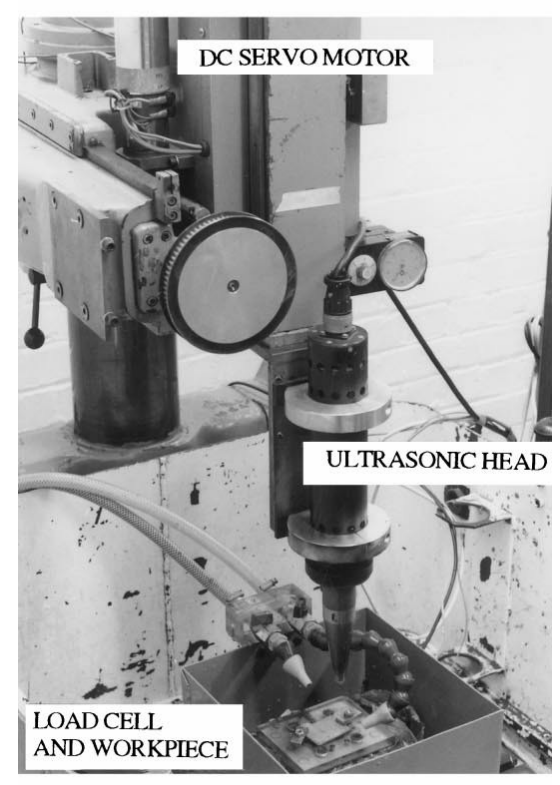

b)

Fig. 45. Views of the experimental set-up [167]

\section{Future research opportunities}


The review of present literature gives chances for novel commercial, technological and scientific advancements in the field of hybrid micro-machining processes, some of which are explained in the following.

\subsection{Study on mechanisms involved in processes}

Within hybrid micro-machining processes different forms of energy or forms of energy caused in different ways are used at the same time at the same zone of impact. Hence, further research is required in order to fully understand the mechanics and mechanisms involved in hybrid micro-machining processes which is primarily influenced by simultaneous combination of processes and or energy sources, and requires extensive research in chip removal process.

\subsection{Research on modelling techniques}

More research on numerical and multiscale modelling approaches is required in order to simulate the hybrid micro-machining processes. Finite element analysis, multiphysics modelling, molecular dynamic simulation and etc. can be combined in order to simulate hybrid micro-machining processes. Development of such modelling methods will aid in gaining better understanding and optimizing these processes.

\subsection{Development of specific multi-axis ultraprecision machine tools}

Since hybrid micro-machining processes are based on the simultaneous and controlled interaction of process mechanisms and/or energy sources/tools, specific multi-axis 
ultraprecision machine tools are required to be developed considering tough requirements such as high thermal stability, high static and dynamic stiffness, feed drives and control systems with high accuracy and short response time associated with large bandwidth and low following error for multi-axes interpolation, low deformation and vibration, precise spindle bearings and linear guides and high resolution of linear and rotary motions, minimization and/or compensation of thermal effects and minimization and compensation of static and dynamic positioning errors. Multi-axis ultraprecision machine tools are also needed to be developed for hybrid micro-machining processes in order to perform various tasks in diverse directions and angles. Furthermore, an enhanced numerical control is necessary to achieve smooth tool movements without changes in the feed rate, responsible for high accuracies of micro-structures.

\subsection{Opportunities for improving process monitoring techniques}

Process monitoring systems are needed to characterize, control, and improve hybrid micromachining processes. Monitoring may be applied to parameters or variables such as temperature, cutting force, chatter, vibration, etc. Process monitoring through acoustic emission, force and vibration signals draw a great deal of attention. However, it is desirable to use multiple sensors to realize the smart and intelligent machine tool [6].

\subsection{Development of on-machine tool fabrication and metrology techniques}

The motivation of on-machine tool making is to avoid realignment and clamping errors. Thus, on-machine tool fabrication methods can be developed and integrated with hybrid micro-machining processes. Another crucial facet needs to be considered is uncertainty of the 
achievable accuracy in hybrid micro-machining processes. A non-contact, on-machine metrology system is indispensable to achieve and maintain high quality of the machined micro-parts and avoid error introduced by the re-fixture after the offline measurement.

\subsection{Establishment of novel processes}

Necessities for the fabrication of miniature/micro-products with complex shapes have made new challenges for designing new hybrid micro-machining processes. A few numbers of hybrid micro-machining processes have been developed for manufacturing 3D complex micro-components. Table 5 lists the major hybrid and combination of hybrid micromachining with other micro-machining and assisted techniques that can be regarded as effective and successful processes for manufacturing 3D micro-structures.

Table 5. Successful hybrid and combination of hybrid micro-machining with other micromachining and assisted techniques

\begin{tabular}{|c|c|c|c|}
\hline Hybrid process & Successful sub-process & Feasible material & $\begin{array}{l}\text { Geometric } \\
\text { complexity }\end{array}$ \\
\hline \multirow{3}{*}{ 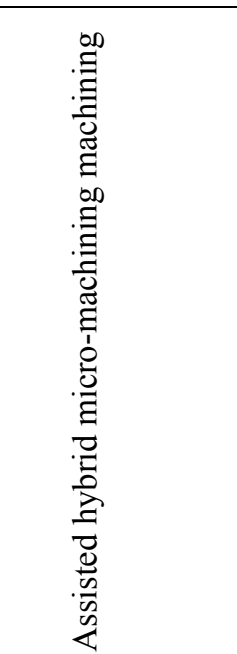 } & Vibration-assisted milling/grinding & $\begin{array}{c}\text { Conductive, Non- } \\
\text { conductive materials, } \\
\text { Polymers }\end{array}$ & $3 \mathrm{D}$ \\
\hline & Vibration-assisted EDM milling & Conductive materials & $3 \mathrm{D}$ \\
\hline & Laser-assisted milling/grinding & $\begin{array}{l}\text { Conductive, Non- } \\
\text { conductive materials, } \\
\text { Hard-brittle materials }\end{array}$ & $3 \mathrm{D}$ \\
\hline
\end{tabular}




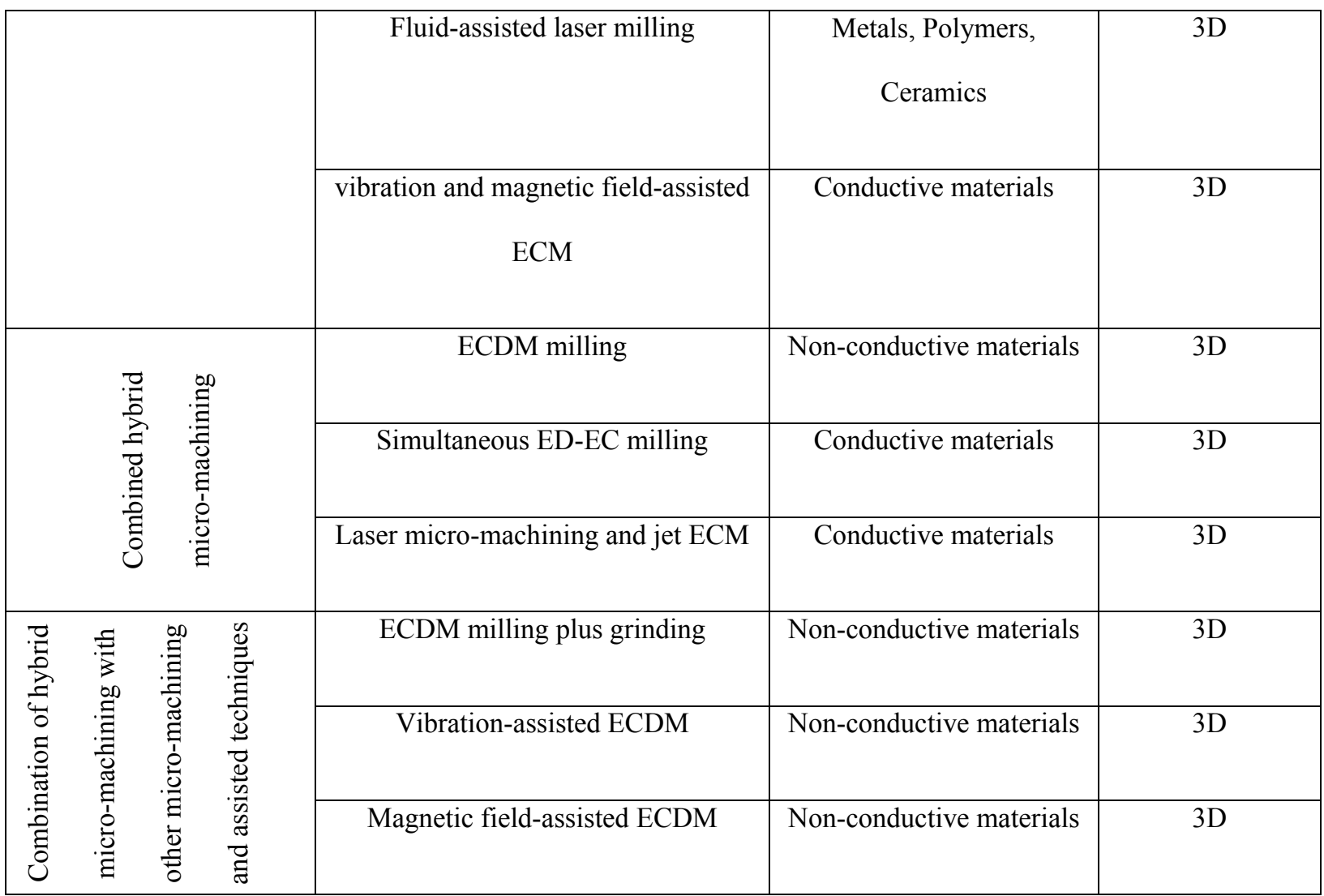

Majority of published researches $(70.4 \%)$ on the hybrid micro-machining possesses is dealing with assisted hybrid micro-machining, as illustrated in Fig. 46. Around 58\% of all the work on assisted hybrid micro-machining has been performed on studying vibration-assisted processes. This area of research has been important due to simplicity as well as superior improvements of micro-machining performance. Moreover, about $21 \%$ of researches have been carried out on the laser-assisted micro-machining. Laser-assisted micro-milling/grinding are among favourable hybrid processes which are able to generate a wide variety of complex micro-components on hard-brittle materials and thus they can be developed more and combined with other types of energy such as ultrasonic vibration, magnetic field and etc. It can be seen from Fig. 46 (left pie chart) that about $67.5 \%$ of all the researches on combined hybrid micro-machining have been carried out on the ECDM as this process is an excellent choice for micro-machining of complex shapes made of hard-brittle and non-conductive materials. SEDCM $(17.5 \%)$ is a relatively new process that can be used for micro-machining 
3D structures made of conductive materials. It is obvious from Fig. 46 that very few investigations (nearly 7.5\%) have been carried out on some other novel assisted and combined hybrid micro-machining processes. Hence, an interesting research area is to propose novel and flexible hybrid micro-machining processes which have the capability of producing free-form surfaces. In order to reach this goal, mechanical, chemical, electrochemical and thermal micro-machining processes as well as various sorts of energy can be integrated in the future work. Furthermore, integration of hybrid micro-machining processes with other micro-machining and assisted methods can be considered as another fascinating subject as it would overcome various shortcomings faced in the single hybrid micro-machining processes.

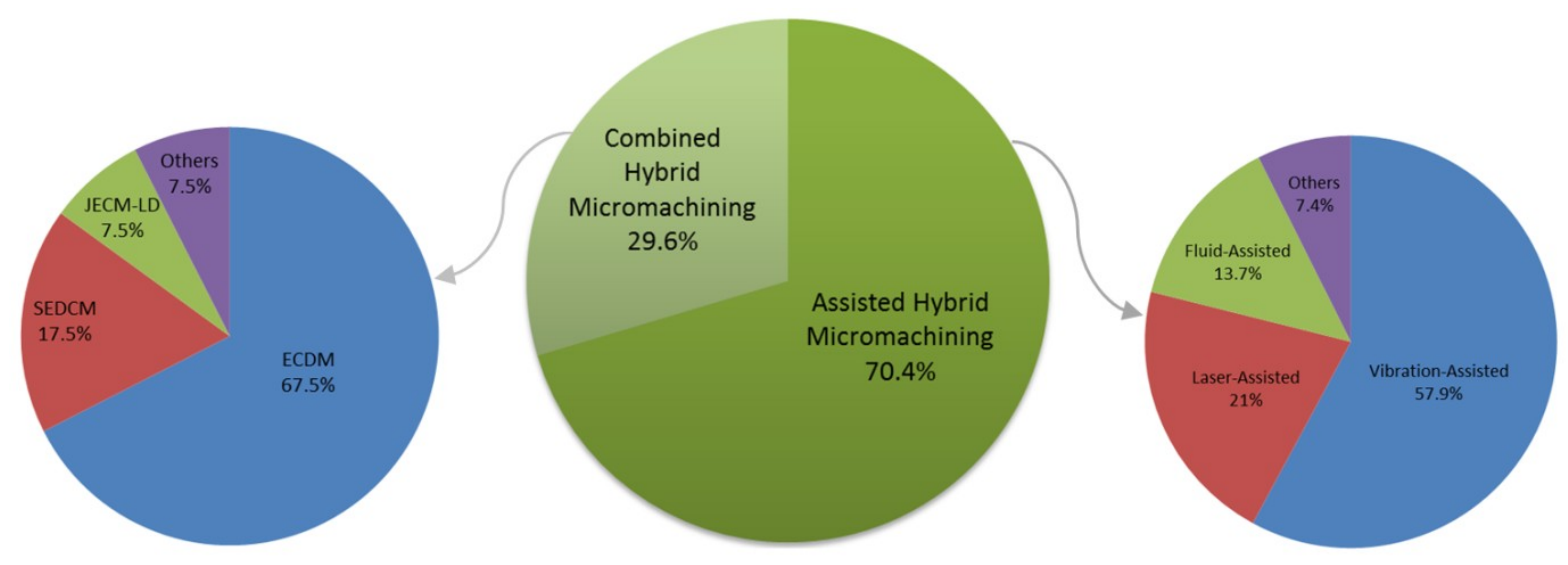

Fig. 46. Percentage of research performed in hybrid micro-machining processes

\subsection{Cost effectiveness study}

Cost effectiveness is a crucial facet needs to be considered when developing hybrid micromachining processes. The major components to be considered in calculating the cost effectiveness of one hybrid micro-machining technique versus another single micro- 
machining process can be the initial capital investment, total micro-machining time, micromachining cost per minute, labour cost per minute, flexibility and product quality.

\subsection{Industrial implementation}

Majority of hybrid micro-machining processes are still at the research stage, and only a few of them have so far found their way into industrial applications. Technology transfer is known to be a difficult process. A typical technology takes up several years to move from the research laboratory to become a general practice in industry. Industry uses several investigative methods before adopting a new technology. As discussed earlier, cost effectiveness is a momentous aspect which is considered by industry. More research on industrial implementation of hybrid micro-machining processes is required to be performed.

\section{Conclusion}

Hybrid micro-machining processes enable us to improve process capabilities in terms of the surface roughness, material removal rate, tool life and geometrical accuracy. To fabricate complex micro-parts on hard-to-machine and multi-materials, a hybrid micro-machining process can be extremely beneficial so as to obtain higher machining efficiency. However, relying on a proper comprehension of the process-material interaction, process parameters should be opted in an appropriate approach. Otherwise, undesirable consequences such as deteriorated surface finish, micro-cracks, etc. can be obtained.

From the literature review presented in this paper, it is evident that a few attempts have been made to develop novel combined hybrid micro-machining processes. The authors believe that combined hybrid micro-machining processes have great potential for fabricating 3D complex 
micro-components with high accuracy and surface quality. Among them, ECDM milling is a promising process for micro-machining complex shapes made of hard-brittle and nonconductive materials. Moreover, laser-assisted micro-milling has the capability to produce free-form surfaces on hard-brittle and non-conductive materials. These processes can be integrated with other assisted and sequential processes so as to improve surface integrity, machining rate and geometrical accuracy of the machined micro-parts.

Hybrid micro-machining processes are just starting to be developed in many features, leaving ample opportunity for future investigation. The process mechanisms, simulation methods, ultraprecision machine tools for hybrid micro-machining, process monitoring and metrology techniques, novel hybrid micro-machining techniques, cost effectiveness and industrial implementation are among those scopes need to be explored.

\section{Acknowledgment}

The authors would like to thank EPSRC (EP/K018345/1) to provide financial support to this research.

\section{References}

[1] M.D. Nguyen, Simultaneous micro-EDM and micro-ECM in low-resistivity deionized water, $\mathrm{PhD}$ thesis, National University of Singapore, 2013

[2] W. Chang, Development of Hybrid Micro Machining Approaches and Test-bed, PhD thesis, Heriot-Watt University, 2012

[3] P. Rai-Choudhury, Handbook of lithography, micromachining and microfabrication, SPIE Press. (1997) 
[4] M. J. Madou, Fundamentals of microfabrication and nanotechnology. 3rd edition, CRC Press (2009)

[5] P. Cardoso, J. P. Davim, A brief review on micro-machining of materials. Rev. Adv. Mater. Sci. 30 (2012) 98-102

[6] P. Piljek, Z. Keran, M. Math, Micro-machining-review of literature from 1980 to 2010. Interdisciplinary Description of Complex Systems 12 (1) (2014) 1-27

[7] MEMS/NEMS Handbook Techniques and Applications Volume 3, Edited by Cornelius T. Leondes, (2006) Springer publications

[8] X. Luo, K. Cheng, D. Web, F. Wardle, Design of ultraprecision machine tools with applications to manufacture of miniature and micro components, Journal of Materials Processing Technology. 167 (2005) 515-528.

[9] H. El-Hofy, Advanced machining processes, McGraw-Hill, 2005

[10] Z. Zhu , V.G. Dhokia, A. Nassehi, S.T. Newman, A review of hybrid manufacturing processes-state of the art and future perspectives, International Journal of Computer Integrated Manufacturing. 26:7 (2013) 596-615

[11] K.P. Rajurkara, D. Zhua, J.A. McGeoughb, J. Kozakc, A. De Silva, New developments in electrochemical machining. CIRP Annals: Manufacturing Technology. 48 (2) (1999) $567-$ 579.

[12] J. Kozak, K.P. Rajurkar, Hybrid machining process evaluation and development, Proceedings of 2nd International conference on machining and measurements of sculptured surfaces, Keynote Paper, 20-22 September, Krakow, Poland. Krakow: The Institute of Metal Cutting (IOS), (2000) 501-536. 
[13] D.K. Aspinwall, R.C. Dewes, J.M. Burrows, M.A. Paul, Hybrid high speed machining (HSM): system design and experimental results for grinding/HSM and EDM/HSM, CIRP Annals-Manufacturing Technology, 50 (1) (2001) 145-148.

[14] D.T. Curtis, S.L. Soo, D.K. Aspinwall, C. Sage, Electrochemical superabrasive machining of a nickel-based aeroengine alloy using mounted grinding points, CIRP AnnalsManufacturing Technology. 58 (1) (2009) 173-176.

[15] B. Lauwersa, Surface Integrity in Hybrid Machining Processes, Procedia Engineering 19 (2011) 241-251.

[16] C.H. She, C.W. Hung, Development of multi-axis numerical control program for millturn machine, Proceedings of the Institution of Mechanical Engineers Part B-Journal of Engineering Manufacture. 222 (6) (2008) 741-745.

[17] B. Lauwers, F. Klocke, A. Klink, A. Erman Tekkaya, R. Neugebauer, D. Mcintosh, Hybrid processes in manufacturing. CIRP Annals - Manufacturing Technology 63 (2014) $561-583$

[18] U. Heisel, R. Eisseler, R. Eber, J. Wallaschek, J. Twiefel, M. Huang, Ultrasonic-assisted machining of stone, Prod. Eng. Res. Devel. (2011) 5:587-594

[19] D.E. Brehl, T.A. Dow, Review of vibration-assisted machining, Precision Engineering. $32(2008) 153-172$.

[20] T. Tawakoli, B. Azarhoushang, M. Rabiey, Ultrasonic assisted dry grinding of 42CrMo4, Int J Adv Manuf Technol. (2009) 42:883-891.

[21] B. Azarhoushang, J. Akbari, Ultrasonic-assisted drilling of Inconel 738-LC, International Journal of Machine Tools \& Manufacture. 47 (2007) 1027-1033. 
[22] K.M. Li, S. L. Wang, Effect of tool wear in ultrasonic vibration-assisted micro-milling, Proc IMechE Part B: J Engineering Manufacture, 228(6) (2014) 847-855 .

[23] H. Onikura, R. Inoue, K. Okuno, O. Ohnishi, Fabrication of Electroplated Micro Grinding Wheels and Manufacturing of Micro-structures with Ultrasonic Vibration, Key Engineering Materials. 238-239 (2003) 9-14.

[24] H. Onikura, O. Ohnishi, Y. Take, Fabrication of Micro Carbide Tools by Ultrasonic Vibration Grinding, CIRP Annals - Manufacturing Technology, 49(1) (2000) 257-260

[25] J. S. Lee, D. W. Lee, Y. H. Jung, W. S. Chung, A study on micro-grooving characteristics of planar lightwave circuit and glass using ultrasonic vibration cutting, Journal of Materials Processing Technology. 130-131 (2002) 396-400

[26] A. H. Ammouri, R. F. Hamade, BUEVA: a bi-directional ultrasonic elliptical vibration actuator for micro-machining, Int J Adv Manuf Technol. 58 (2012) 991-1001

[27] G. D. Kim, B. G. Loh, Direct Machining of Micro Patterns on Nickel Alloy and Mold Steel by Vibration Assisted Cutting, International journal of precision engineering and manufacturing 12(4) (2011) 583-588.

[28] G. D. Kim, B. G. Loh, Cutting Force Variation with Respect to Tilt Angle of Trajectory in Elliptical Vibration V-grooving, International journal of precision engineering and manufacturing. 14(10) (2013)1861-1864.

[29] B. Brocato, Micro-machining Using EVAM (Elliptical Vibration Assisted Machining), Master's Thesis, North Carolina State University, 2005. 
[30] D. E. Brehl, T.A. Dow, 3-D micro-structure creation using elliptical vibration assisted machining, ASPE Proceedings, Vibration Assisted Machining Technology, April 16-17, (2007), The Carolina Inn, Chapel Hill, NC.

[31] C. Huawei, C. Minglong, L. Youjie, Z. Deyuan, Development of Integrated Precision Vibration-Assisted Micro-Engraving System, Trans. Tianjin Univ. 17 (2011) 242-247.

[32] S. Koshimizu, S. Aoki, Micro-Grooving of Glass Using Small-Diameter Diamond Grindstone with Ultrasonic Vibration, Advanced Materials Research. 797 (2013) 368-373.

[33] Z. Z. Wang, Y. B. Guo, Y. B. Wu, Development of a Two-dimensional Ultrasonic Vibration Assisted Machining Technology with Tool Vibration, Key Engineering Materials. 487 (2011) 419-422.

[34] C. Zhang, E. Brinksmeier, R. Rentsch, Micro-USAL technique for the manufacture of high quality micro-structures in brittle materials, Precision Engineering 30 (2006) 362-372.

[35] C. Zhang, R. Rentsch, E. Brinksmeier, Advances in micro ultrasonic assisted lapping of micro-structures in hard-brittle materials: a brief review and outlook, International Journal of Machine Tools \& Manufacture. 45 (2005) 881-890

[36] H. Suzuki, T. Moriwaki, T. Okino, Y. Ando, Development of Ultrasonic Vibration Assisted Polishing Machine for Micro Aspheric Die and Mold, CIRP Annals - Manufacturing Technology. 55 (1) (2006) 385-388.

[37] H. Suzuki, S. Hamada, T. Okino, M. Kondo, Y. Yamagata, T. Higuchi, Ultraprecision finishing of micro-aspheric surface by ultrasonic two-axis vibration assisted polishing, CIRP Annals - Manufacturing Technology. 59 (2010) 347-350. 
[38] S. K. Chee, H. Suzuki, M. Okada, T. Yano, T. Higuchi, W. Lin, Precision Polishing of Micro Mold by Using Piezoelectric Actuator Incorporated with Mechanical Amplitude Magnified Mechanism, Advanced Materials Research. 325 (2011) 470-475.

[39] T. Endo, T. Tsujimoto, K. Mitsui, Study of vibration-assisted micro-EDM-The effect of vibration on machining time and stability of discharge, Precision Engineering. 32 (2008) 269277.

[40] M. Mahardika, G. S. Prihandana, T. Endo, T. Tsujimoto, N. Matsumoto, B. Arifvianto, K. Mitsui, The parameters evaluation and optimization of polycrystalline diamond microelectrodischarge machining assisted by electrode tool vibration, Int J Adv Manuf Technol. 60 (2012) 985-993.

[41] H. Huang, H. Zhang, L. Zhou, H. Y. Zheng, Ultrasonic vibration assisted electrodischarge machining of microholes in Nitinol, J. Micromech. Microeng. 13 (2003) 693-700.

[42] D. Ghiculescu, N. I. Marinescu, S. Nanu, D. Ghiculescu, G. Kakarelidis, FEM study of synchronization between pulses and tool oscillations at ultrasonic aided microelectrodischarge machining, Nonconventional Technologies Review. 3 (2010)19-25.

[43] A. W. J. Hsue, J.J. Wang, C. H. Chang, Milling Tool of Micro-EDM by Ultrasonic Assisted Multi-axial Wire Electrical Discharge Grinding Processes, Proceedings of the ASME 2012 International Manufacturing Science and Engineering Conference MSEC2012 June 4-8, (2012) Notre Dame, Indiana, USA.

[44] S. Mastud, M. Garg, R. Singh, J. Samuel, S. Joshi, Experimental characterization of vibration-assisted reverse micro electrical discharge machining (EDM) for surface texturing, 
Proceedings of the ASME 2012 International Manufacturing Science and Engineering Conference MSEC2012,June 4-8, (2012) Notre Dame, Indiana, USA.

[45] A. Ruszaj, M. Zybura, R. Zurek, G. Skrabalak, Some aspects of the electrochemical machining process supported by electrode ultrasonic vibrations optimization, Proceedings of the Institution of Mechanical Engineers, Part B: Journal of Engineering Manufacture. 217 (2003) 1365-1371.

[46] B. Bhattacharyya, M. Malapati, J. Munda, A. Sarkar, Influence of tool vibration on machining performance in electrochemical micro-machining of copper, International Journal of Machine Tools \& Manufacture. 47 (2007) 335-342.

[47] B. Ghoshal, B. Bhattacharyya, Influence of vibration on micro-tool fabrication by electrochemical machining, International Journal of Machine Tools \& Manufacture. 64 (2013) 49-59.

[48] B. Ghoshal, B. Bhattacharyya, Shape control in micro borehole generation by EMM with theassistance of vibration of tool, Precision Engineering. 38 (2014) 127-137.

[49] G. L. Chern, Y. C. Chang, Using two-dimensional vibration cutting for micro-milling, International Journal of Machine Tools \& Manufacture. 46 (2006) 659-666.

[50] G. L. Chern, H. J. Lee, Using workpiece vibration cutting for micro-drilling, Int J Adv Manuf Technol. 27 (2006) 688-692.

[51] H. Lian, Z. Guo, Z. Huang, Y. Tang, J. Song, Experimental research of A16061 on ultrasonic vibration assisted micro-milling, Procedia CIRP 6 ( 2013 ) 561-564. 
[52] J. H. Ko, K. C. Shaw, H. K. Chua, R. M. Lin, Cusp Error Reduction under High Speed Micro/Meso-Scale Milling with Ultrasonic Vibration Assistance, International journal of precision engineering and manufacturing. 12(1) (2011) 15-20.

[53] K. Egashira, K. Mizutani,T. Nagao, Ultrasonic Vibration Drilling of Microholes in Glass, CIRP Annals - Manufacturing Technology. 51(1) (2002) 339-342.

[54] M. Aziz, O. Ohnishi, H. Onikura, Novel micro deep drilling using micro long flat drill with ultrasonic vibration, Precision Engineering. 36 (2012) 168-174.

[55] A. C. Wang, B. H. Yan, X. T. Li, F. Y. Huang, Use of micro ultrasonic vibration lapping to enhance the precision of microholes drilled by micro electrodischarge machining, International Journal of Machine Tools \& Manufacture. 42 (2002) 915-923.

[56] C. Gao, Z. Liu, A study of ultrasonically aided micro-electrical-discharge machining by the application of workpiece vibration, Journal of Materials Processing Technology. 139 (2003) 226-228.

[57] M. P. Jahan, T. Saleh, M. Rahman, Y. S. Wong, Development, Modeling, and Experimental Investigation of Low Frequency Workpiece Vibration-Assisted Micro-EDM of Tungsten Carbide, J. Manuf. Sci. Eng. 132(5) (2010) 054503.

[58] M.P. Jahan, T. Saleh, M. Rahman, Y.S. Wong, Study of Micro-EDM of Tungsten Carbide with Workpiece Vibration, Advanced Materials Research, , 264-265 (2011) 10561061.

[59] M. P. Jahan, M. Rahman, Y. S. Wong, L. Fuhua, On-machine fabrication of high-aspectratio micro-electrodes and application in vibration-assisted micro-electrodischarge drilling of tungsten carbide, Proceedings of the Institution of Mechanical Engineers, Part B: Journal of Engineering Manufacture. 224 (2010) 795-814. 
[60] M.P. Jahan, Y.S. Wong, M. Rahman, Evaluation of the effectiveness of low frequency workpiece vibration in deep-hole micro-EDM drilling of tungsten carbide, Journal of Manufacturing Processes 14 (2012) 343-359.

[61] J. C. Hung, J. K. Lin, B. H. Yan, H. S. Liu, P. H. Ho, Using a helical micro-tool in micro-EDM combined with ultrasonic vibration for micro-hole machining, J. Micromech. Microeng. 16 (2006) 2705-2713.

[62] H. Tong, Y. Li, Y. Wang, Experimental research on vibration assisted EDM of microstructures with non-circular cross-section, Journal of materials processing technology. 208 (2008) 289-298.

[63] R. Garna, A. Schubert, H. Zeidler, Analysis of the effect of vibrations on the microEDM process at the workpiece surface, Precision Engineering. 35 (2011) 364-368.

[64] Z.Y. Yu, Y. Zhang, J. Li, J. Luan, F. Zhao, D. Guo, High aspect ratio micro-hole drilling aided with ultrasonic vibration and planetary movement of electrode by micro-EDM, CIRP Annals - Manufacturing Technology. 58 (2009) 213-216.

[65] M. M. Sundaram, G. B. Pavalarajan, K. P. Rajurkar, A Study on Process Parameters of Ultrasonic Assisted Micro EDM Based on Taguchi Method, Journal of Materials Engineering and Performance. 17 (2008) 210-215.

[66] H. Tong, Y. Li, Y. Wang, Vibration-assisted servo scanning 3D micro EDM, J. Micromech. Microeng. 18 (2008) 025011.

[67] K.T. Hoang, S.H. Yang, A study on the effect of different vibration-assisted methods in micro-WEDM, Journal of Materials Processing Technology. 213 (2013) 1616-1622. 
[68] Z. Liu, H. Zhang, H. Chen, Y. Zeng, Investigation of material removal rate in micro electrochemical machining with lower frequency vibration on workpiece, Int. J. Machining and Machinability of Materials. 14(1) (2013) 91-104.

[69] B. Kang, G. W. Kim, M. Yang, S. H. Cho, J. K. Park, A study on the effect of ultrasonic vibration in nanosecond laser machining, Optics and Lasers in Engineering. 50 (2012) 18171822

[70] H. Y. Zheng, H. Huang, Ultrasonic vibration-assisted femtosecond laser machining of microholes, J. Micromech. Microeng. 17 (2007) N58-N61.

[71] S. U. Je, D. W. Kim, H. S. Lee, C. N. Chu, Micro EDM with Ultrasonic Work Fluid Vibration for Deep Hole Machining, Journal of the Korean Society of Precision Engineering. $22(7)(2005) 47-53$.

[72] D. J. Kim, S. M. Yi, Y. S. Lee, Ch. N. Chu, Straight hole micro EDM with a cylindrical tool using a variable capacitance method accompanied by ultrasonic vibration, J. Micromech. Microeng. 16 (2006) 1092-1097.

[73] T. Ichikawa, W. Natsu, Study on Machining Characteristics of Ultrasonic Vibration Assisted Micro-EDM, Applied Mechanics and Materials. 217-219 (2012) 2163-2166.

[74] T. Ichikawa, W. Natsu, Realization of micro-EDM under ultra-small discharge energy by applying ultrasonic vibration to machining fluid, Procedia CIRP. 6 (2013) 326-331.

[75] J. K. Park, J. W. Yoon, M. C. Kang, S. H. Cho, Surface effects of hybrid vibrationassisted femtosecond laser system for micro-hole drilling of copper substrate, Trans. Nonferrous Met. Soc. China. 22 (2012) 801-807. 
[76] J. K. Park, J. W. Yoon, S. H. Cho, Vibration assisted femtosecond laser machining on metal, Optics and Lasers in Engineering. 50 (2012) 833-837.

[77] W-S Chu, C-S Kim, H-T Lee, J-O Choi, J-I Park, J-H Song, K-H Jang, S-H Ahn, Hybrid Manufacturing in Micro/Nano Scale: A Review. International journal of precision engineering and manufacturing-green technology 1(1) (2014) 75-92.

[78] S. Sun, M. Brandt, M. S. Dargusch, Thermally enhanced machining of hard-to-machine materials-A review, International Journal of Machine Tools \& Manufacture. 50 (2010) 663 680.

[79] R. K. Singh, Laser Assisted Mechanical Micro-machining of Hard-to-Machine Materials, PhD thesis, Georgia Institute of Technology December 2007.

[80] R. Singh, S. N. Melkote, Characterization of a hybrid laser-assisted mechanical micromachining (LAMM) process for a difficult-to-machine material, International Journal of Machine Tools \& Manufacture. 47 (2007) 1139-1150.

[81] R. Singh, M. J. Alberts, S. N. Melkote, Characterization and prediction of the heataffected zone in a laser-assisted mechanical micro-machining process, International Journal of Machine Tools \& Manufacture. 48 (2008) 994-1004.

[82] A. R. Shayan, H. B. Poyraz, D. Ravindra, M. Ghantasala, J. A. Patten, Force analysis, mechanical energy and laser heating evaluation of scratch tests on silicon carbide $(4 \mathrm{H}-\mathrm{SiC})$ in micro-laser assisted machining ( $\mu$-lam) process, Proceedings of the ASME 2009 International Manufacturing Science and Engineering Conference, MSEC2009, October 4-7, (2009), West Lafayette, Indiana, USA.

[83] M. Kumar, Laser assisted micro milling of hard materials, $\mathrm{PhD}$ thesis, Georgia Institute of Technology, 2011. 
[84] S. Melkote, M. Kumar, F. Hashimoto, G. Lahoti, Laser assisted micro-milling of hardto-machine materials, CIRP Annals - Manufacturing Technology. 58 (2009) 45-48.

[85] M. Kumar, S. N. Melkote, Process capability study of laser assisted micro milling of a hard-to-machine material, Journal of Manufacturing Processes. 14 (2012) 41-51.

[86] M. Kumar, S. N. Melkote, R. M'Saoubi, Wear behavior of coated tools in laser assisted micro-milling of hardened steel, Wear. 296 (2012) 510-518.

[87] N. Shen, H. Ding, Thermo-mechanical Coupled Analysis of Laser-assisted Mechanical Micromilling of Difficult-to-machine Metal Alloys Used for Bio-implant, International journal of precision engineering and manufacturing. 14(10) (2013)1677-1685.

[88] H. Ding, N. Shen, Y. C. Shin, Thermal and mechanical modeling analysis of laserassisted micro-milling of difficult-to-machine alloys, Journal of Materials Processing Technology. 212 (2012) 601- 613.

[89] Z. Mohid, N. M.Warap, E. A. Rahim, M. R. Ibrahim, M.I.S Ismail, Study on Laser Assisted Micro Milling (LAMM) Processing Characteristic Titanium Alloy (Ti6A14V) using TiAlN coated carbide micro ball mill, International conference on micromanufacturing (ICOMM) (2014), No. 31.

[90] Z. Mohid, N. M. Warap, S. Hassan, M.I.S. Ismail, R. Ibrahim, E. A. Rahim, Numerical Analysis of Laser Heating for Laser Assisted Micro Milling Application, Applied Mechanics and Materials. 465-466 (2014) 720-724.

[91] E. A. Rahim, Z. Mohid, N. M. Warap, M. R. Ibrahim, M.I.S Ismail, A Prediction of Laser Spot-to-Cutting Tool Distance in Laser Assisted Micro Milling, International conference on micromanufacturing (ICOMM) (2014) No. 32. 
[92] W. Chang, X. Luo, Q. Zhao, J. Sun, Y. Zhao, Laser assisted micro grinding of high strength materials, Key Engineering Materials. 496 (2012) 44-49.

[93] A. K. M. De Silva, P. T. Pajak, D. K. Harrison, J. A. McGeough, Modelling and Experimental Investigation of Laser Assisted Jet Electrochemical Machining. CIRP Annals Manufacturing Technology, 53 (1) (2004) 179-182

[94] P. T. Pajak, A. K. M. De Silva, D. K. Harrison, J. A. McGeough, Precision and Efficiency of Laser Assisted Jet Electrochemical Machining. Precision Engineering, 30 (3) (2006) 288-298

[95] A. K. M. De Silva, P. T. Pajak, J. A. McGeough, D. K. Harrison, Thermal Effects in Laser Assisted Jet Electrochemical Machining. CIRP Annals - Manufacturing Technology, 60 (1) (2011) 243-246

[96] P. T. Pajak, A. K. M. De Silva, J. A. McGeough, D. K. Harrison., Modelling the Aspects of Precision and Efficiency in Laser-Assisted Jet Electrochemical Machining (LAJECM). Journal of Materials Processing Technology, 149 (1-3) (2004) 512-518

[97] V. Tangwarodomnukun, Towards damage-free micro-fabrication of silicon substrates using a hybrid laser-waterjet technology, PhD Thesis, The University of New South Wales, 2012.

[98] V. Tangwarodomnukun, J. Wanga, C.Z. Huang, H.T. Zhu, An investigation of hybrid laser-waterjet ablation of silicon substrates, International Journal of Machine Tools \& Manufacture. 56 (2012) 39-49.

[99] J. J. J. Kaakkunen, M. Silvennoinen, K. Paivasaari, P. Vahimaa, Water-Assisted Femtosecond Laser Pulse Ablation of High Aspect Ratio Holes, Physics Procedia. 12 (2011) 89-93. 
[100] L. M. Wee, E. Y. K. Ng, A. H. Prathama, H. Zheng, Micro-machining of silicon wafer in air and under water, Optics \& Laser Technology. 43 (2011) 62-71.

[101] C-H Tsai, C-C Li, Investigation of underwater laser drilling for brittle substrates. Journal of materials processing technology 209 (2009) 2838-2846

[102] D. J. Hwang, T. Y. Choi, C. P. Grigoropoulos, Liquid-assisted femtosecond laser drilling of straight and three-dimensional microchannels in glass. Appl. Phys. A 79 (2004) $605-612$

[103] K. L. Choo, Y. Ogawa, G. Kanbargi, V. Otra, L.M. Raff, R. Komanduri, Micromachining of silicon by short-pulse laser ablation in air and under water, Materials Science and Engineering A. 372 (2004) 145-162.

[104] D. Jang, D Kim, Liquid-assisted excimer laser micromaching for ablation enhancement and debris reduction. Journal of Laser Micro/Nanoengineering (2006) 1 (3) 221-225

[105] H. K. Sezer, L. Li, S. Leigh, Twin gas jet-assisted laser drilling through thermal barriercoated nickel alloy substrates. International Journal of Machine Tools \& Manufacture 49 (2009) 1126-1135

[106] L. M. Wee, L. E. Khoong, C. W. Tan, G. C. Lim, Solvent-Assisted Laser Drilling of Silicon Carbide, Int. J. Appl. Ceram. Technol. 8 (6) (2011)1263-1276.

[107] L. Li, C. Achara, "Chemical assisted laser machining for the minimisation of recast and heat affected zone,” CIRP Annals - Manufacturing Technology, 53 (1) (2004) 175-178

[108] J. P. Choi, B. H. Jeon, B. H. Kim, Chemical-assisted ultrasonic machining of glass, Journal of Materials Processing Technology. 191 (2007) 153-156. 
[109] S. Sebastian, G. Marcin, S. Maciej, Experimental Research on Electrochemically Assisted Microturning Process, Key Engineering Materials. 611-612 (2014) 701-707.

[110] W. M. Winslow, Induced vibration of suspensions. J. Appl. Phys. 20 (1949) 1137-1140

[111] Y. Y. Tsai, C. H. Tseng, C. K. Chang, Development of a combined machining method using electrorheological fluids for EDM, Journal of materials processing technology. 201 (2008) 565-569.

[112] T. Tateishi, N. Yoshihara, J. Yan, T. Kuriyagawa, Study on electrorheological fluidassisted microultrasonic machining, Int. J. Abrasive Technology. 2 (2009) 70-82.

[113] T. Tateishi, N. Yoshihara, J. Yan, T. Kuriyagawa, Fabrication of high-aspect ratio micro holes on hard brittle materials-Study on electrorheological fluid-assisted micro ultrasonic machining, Key Engineering Materials. 389-390 (2009) 264-270.

[114] T. Tateishi, K. Shimada, N. Yoshihara, J. W. Yan, T. Kuriyagawa, Effect of Electrorheological Fluid Assistance on Micro Ultrasonic Machining, Advanced Materials Research. 69-70 (2009) 148-152.

[115] S. H. Yeo, M. Murali, H. T. Cheah, Magnetic field assisted micro electrodischarge machining, J. Micromech. Microeng. 14 (2004) 1526-1529.

[116] H. Y. Zheng, Z.W. Jiang, Femtosecond laser micro-machining of silicon with an external electric field, J. Micromech. Microeng. 20 (2010) 017001.

[117] P. J. Liew, J. Yan, T. Kuriyagawa, Carbon nanofiber assisted micro electro discharge machining of reaction-bonded silicon carbide, Journal of Materials Processing Technology. 213 (2013) 1076-1087. 
[118] P. S. Pa, Super finishing with ultrasonic and magnetic assistance in electrochemical micro-machining, Electrochimica Acta. 54 (2009) 6022-6027.

[119] J. Guo, H. Suzuki, T. Higuchi, Development of micro polishing system using a magnetostrictive vibrating polisher, Precision Engineering. 37 (2013) 81-87.

[120] J. Guo, S. Y. Morita, M. Hara, Y. Yamagata, T. Higuchi, Ultra-precision finishing of micro-aspheric mold using a magnetostrictive vibrating polisher, CIRP Annals Manufacturing Technology. 61 (2012) 371-374.

[121] J. Guo, H. Suzuki, S. Y. Morita, Y. Yamagata, T. Higuchi, Micro Polishing of Tungsten Carbide using Magnetostrictive Vibrating Polisher, Key Engineering Materials. 516 (2012) 569-574.

[122] B. Bhattacharyya, B. N. Doloi, S. K. Sorkhel, Experimental investigations into electrochemical discharge machining $(\mathrm{ECDM})$ of non-conductive ceramic materials, Journal of Materials Processing Technology. 95 (1-3) (1999) 145-154.

[123] S. K. Jui, A. B. Kamaraj, M. M. Sundaram, High aspect ratio micro-machining of glass by electrochemical discharge machining (ECDM). Journal of Manufacturing Processes 15 (2013) 460-466

[124] P. K. Gupta, A. Dvivedi, P. Kumar, Developments on electrochemical discharge machining: A review of experimental investigations on tool electrode process parameters. Proc IMechE Part B: J Engineering Manufacture (2014) doi: 10.1177/0954405414534834

[125] R. Wuthricha, V. Fascio, Machining of non-conducting materials using electrochemical discharge phenomenon-an overview, International Journal of Machine Tools \& Manufacture. 45 (2005) 1095-1108. 
[126] R. Wuthrich, L. A. Hof, A. Lal, K. Fujisaki, H. Bleuler, P. H. Mandin, G. Picard, Physical principles and miniaturization of spark assisted chemical engraving (SACE), J. Micromech. Microeng. 15 (2005) S268-S275.

[127] R. Wuthrich, L.A. Hof, The gas film in spark assisted chemical engraving (SACE)- A key element for micro-machining applications, International Journal of Machine Tools \& Manufacture. 46 (2006) 828-835.

[128] R. Wuthrich, U. Spaelter, Y. Wu, H. Bleuler, A systematic characterization method for gravity-feed micro-hole drilling in glass with spark assisted chemical engraving (SACE), J. Micromech. Microeng. 16 (2006) 1891-1896.

[129] B. R. Sarkar, B. Doloi, B. Bhattacharyya, Parametric analysis on electrochemical discharge machining of silicon nitride ceramics, Int J Adv Manuf Technol. 28 (2006) 873881.

[130] D. J. Kim, Y. Ahn, S. H. Lee, Y. K. Kim, Voltage pulse frequency and duty ratio effects in an electrochemical discharge microdrilling process of Pyrex glass, International Journal of Machine Tools \& Manufacture. 46 (2006) 1064-1067.

[131] P. Maillard, B. Despont, H. Bleuler, R. Wuthrich, Geometrical characterization of micro-holes drilled in glass by gravity-feed with spark assisted chemical engraving (SACE), J. Micromech. Microeng. 17 (2007) 1343-1349.

[132] J. West, A. Jadhav, ECDM methods for fluidic interfacing through thin glass substrates and the formation of spherical microcavities, J. Micromech. Microeng. 17 (2007) 403-409.

[133] K. Furutani, H. Maeda, Machining a glass rod with a lathe-type electrochemical discharge machine, J. Micromech. Microeng. 18 (2008) 065006. 
[134] Z. P. Zheng, W. H. Cheng, F. Y. Huang, B. H. Yan, 3D microstructuring of Pyrex glass using the electrochemical discharge machining process, J. Micromech. Microeng. 17 (2007) 960-966.

[135] Z. P. Zheng, J. K. Lin, F. Y. Huang, Biing-Hwa Yan, Improving the machining efficiency in electrochemical discharge machining (ECDM) microhole drilling by offset pulse voltage, J. Micromech. Microeng. 18 (2008) 025014.

[136] X. D. Cao, B. H. Kim, C. N. Chu, Micro-structuring of glass with features less than $100 \mu \mathrm{m}$ by electrochemical discharge machining, Precision Engineering. 33 (2009) 459-465.

[137] M. Jalali, P. Maillard, R. Wuthrich, Toward a better understanding of glass gravity-feed micro-hole drilling with electrochemical discharges, J. Micromech. Microeng. 19 (2009) 045001.

[138] B. R. Sarkar, B. Doloi, B. Bhattacharyya, Investigation into the influences of the power circuit on the micro-electrochemical discharge machining process, Proceedings of the Institution of Mechanical Engineers, Part B: Journal of Engineering Manufacture. 223 (2009) $133-144$.

[139] C. P. Cheng, K. L. Wu, C. C. Mai, C. K. Yang, Y. S. Hsu, B. H. Yan, Study of gas film quality in electrochemical discharge machining, International Journal of Machine Tools \& Manufacture. 50 (2010) 689-697.

[140] C. K. Yang, C. P. Cheng, C. C. Mai, A. C. Wang, J. C. Hung, B. H. Yan, Effect of surface roughness of tool electrode materials in ECDM performance, International Journal of Machine Tools \& Manufacture. 50 (2010) 1088-1096. 
[141] C. K. Yang, K. L. Wu, J. C. Hung, S. M. Lee, J. C. Lin, B. H. Yan, Enhancement of ECDM efficiency and accuracy by spherical tool electrode, International Journal of Machine Tools \& Manufacture. 51 (2011) 528-535.

[142] M. Coteaţă, H. P. Schulze, L. Slătineanu, Drilling of Difficult-to-Cut Steel by Electrochemical Discharge Machining, Materials and Manufacturing Processes, 26 (12) (2011)1466-1472.

[143] A. V. Kulkarni, V. K. Jain, K. A. Misra, Electrochemical spark micro-machining (microchannels and microholes) of metals and non-metals, Int. J. Manufacturing Technology and Management. 22( 2) (2011) 107-123.

[144] A. Manna, V. Narang, A study on micro machining of e-glass-fibre-epoxy composite by ECSM process, Int J Adv Manuf Technol. 61 (2012) 1191-1197.

[145] J. D. Abou Ziki, R. Wüthrich, Tool wear and tool thermal expansion during micromachining by spark assisted chemical engraving, Int J Adv Manuf Technol. 61 (2012) 481486.

[146] J. D. Abou Ziki, T. F. Didar, R. Wuthrich, Micro-texturing channel surfaces on glass with spark assisted chemical engraving, International Journal of Machine Tools \& Manufacture. 57 (2012) 66-72.

[147] J. D. Abou Ziki, R. Wüthrich, Forces exerted on the tool-electrode during constant-feed glass micro-drilling by spark assisted chemical engraving, International Journal of Machine Tools \& Manufacture. 73 (2013) 47-54.

[148] L. Paul, S. S. Hiremath, Response Surface Modelling of Micro Holes in Electrochemical Discharge Machining Process, Procedia Engineering. 64 (2013) 1395 -1404. 
[149] H. Krotz, R. Roth, K. Wegener, Experimental investigation and simulation of heat flux into metallic surfaces due to single discharges in micro-electrochemical arc machining (micro-ECAM), Int J Adv Manuf Technol. 68 (2013) 1267-1275.

[150] M. R. Razfar, A. Behroozfar, J. Ni, S. Lan, an investigation on electrochemical discharge micro-drilling of glass, Proceedings of the ASME 2013 International Manufacturing Science and Engineering Conference MSEC2013 June 10-14 (2013) Madison, Wisconsin, USA.

[151] S. F. Huang, Y. Liu, J. Li, H. X. Hu, L. Y. Sun, Electrochemical Discharge Machining Micro-Hole in Stainless Steel with Tool Electrode High Speed Rotating, Materials and Manufacturing Processes. DOI:10.1080/10426914.2014.901523.

[152] L. Paul, S. S. Hiremath, Characterisation of Micro Channels in Electrochemical Discharge Machining Process, Applied Mechanics and Materials. 490-491 (2014) 238-242.

[153] M. D. Nguyen, M. Rahman, Y. S. Wong, Simultaneous micro-EDM and micro-ECM in low-resistivity deionized water, International Journal of Machine Tools and Manufacture. 5455 (2012) 55-65.

[154] M. D. Nguyen, M. Rahman, Y. S. Wong, Enhanced surface integrity and dimensional accuracy by simultaneous micro-ED/EC milling, CIRP Annals - Manufacturing Technology. $61(2012)$ 191-194.

[155] M. D. Nguyen, M. Rahman, Y. S. Wong, Modeling of radial gap formed by material dissolution in simultaneous micro-EDM and micro-ECM drilling using deionized water, International Journal of Machine Tools and Manufacture. 66 (2013) 95-101. 
[156] M. D. Nguyen, M. Rahman, Y. S. Wong, Transitions of micro-EDM/SEDCM/ microECM milling in low-resistivity deionized water, International Journal of Machine Tools and Manufacture. 69 (2013) 48-56.

[157] Y. Qingfeng, W. Baorui, Z. Yongbin, J. Fang, L. Guangmin, Research of lower tool electrode wear in simultaneous EDM and ECM, Journal of Materials Processing Technology. http://dx.doi.org/10.1016/j.jmatprotec.2014.03.0

[158] D. Zhu, Y. B. Zeng, Z. Y. Xu, X. Y. Zhang, Precision machining of small holes by the hybrid process of electrochemical removal and grinding, CIRP Annals - Manufacturing Technology. 60 (2011) 247-250.

[159] Y. Zhao, D. Geng, X. Liu, Study on Combined process of Micro-EDM and Electrorheological Fluid-assisted Polishing, Advanced Materials Research. 418-420 (2011) 1167-1170.

[160] H. Zhang, J. W. Xu, J. M. Wang, Investigation of a Novel Hybrid Process of Laser Drilling Assisted with Jet Electrochemical Machining. Optics and Lasers in Engineering, 47 (11) (2009) 1242-1249

[161] Z. Hua, X. Jiawen, Modeling and Experimental Investigation of Laser Drilling with Jet Electrochemical Machining, Chinese Journal of Aeronautics, 23 (4) (2010) 454-460

[162] H. Zhang, J. W. Xu, Laser drilling assisted with jet electrochemical machining for the minimization of recast and spatter. Int J Adv Manuf Technol 62 (9-12) (2012) -1055-1062

[163] M. S. Han, B. K. Min, S. J. Lee, Geometric improvement of electrochemical discharge micro-drilling using an ultrasonic-vibrated electrolyte, J. Micromech. Microeng. 19 (2009) 065004. 
[164] C. P. Cheng, K. L. Wu, C. C. Mai, Y. S. Hsu, B. H. Yan, Magnetic field-assisted electrochemical discharge machining, J. Micromech. Microeng. 20 (2010) 075019.

[165] X. D. Cao, B. H. Kim, C. N. Chu, Hybrid Micro-machining of Glass Using ECDM and Micro Grinding, International journal of precision engineering and manufacturing. 14(1) (2013) 5-10.

[166] H. S. Liu, B. H. Yan, C. L. Chen, F.Y. Huang, Application of micro-EDM combined with high-frequency dither grinding to micro-hole machining, International Journal of Machine Tools \& Manufacture. 46 (2006) 80-87.

[167] T. B. Thoe, D. K. Aspinwall, N. Killey, Combined ultrasonic and electrical discharge machining of ceramic coated nickel alloy, Journal of Materials Processing Technology. 92-93 (1999) 323-328. 